\title{
ECONOMÍA CIRCULAR APLICADA A LA ARQUITECTURA \\ Espejismo o realidad
}

\author{
CIRCULAR ECONOMY APPLIED TO \\ ARCHITECTURE \\ Illusion or Reality
}

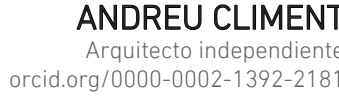

Aunque la sociedad actual parece avanzar lentamente hacia un mundo más sostenible, sigue dependiendo del abastecimiento de recursos naturales cada vez más escasos. Por lo tanto, el modelo consumista — regido por la tríada comprar-usar-tirar - continúa dominando el escenario político-económico mundial. Ante esta situación de desequilibrio entre el consumo de recursos naturales y la producción de desechos, durante los últimos años se ha desarrollado un nuevo modelo económico de carácter cíclico denominado "economía circular", que pretende optimizar la vida de cada material reduciendo el impacto medioambiental que genera su proceso de producción. En este trabajo se analiza la aplicabilidad del modelo circular al ámbito arquitectónico, a través del análisis de experiencias reales, y se propone su aplicación como método constructivo funcional. La arquitectura del futuro ya está construyendo sus cimientos.

sostenibilidad, cradle to cradle, reciclaje, reutilización, economía circular
Recibido: 1 de julio del 2020

Aprobado: 17 de diciembre del 2020

doi: https://doi.org/10.26439/limaq2021.n007.5178

Even though current society seems to be slowly moving toward a more sustainable world, it still depends on the increasingly limited supply of natural resources. Therefore, the consumerist model-governed by the take-make-waste triad-keeps dominating the global political-economic scenario. In this situation of imbalance between the consumption of natural resources and the production of waste, a new economic model of cyclical shape called "circular economy" has been developed in the last few years. Such model aims at optimizing each material's lifetime by reducing the environmental impact generated by its production process. This work examines the applicability of the circular model to the architectural field through the analysis of real experiences and proposes its implementation as a reliable constructive method. Tomorrow's architecture is already building its foundations.

sustainability, cradle to cradle, recycling, reuse, circular economy 
INTRODUCCIÓN

\section{Objetivos}

El principal objetivo de este trabajo es verificar la aplicabilidad de la economía circular en el ámbito de la arquitectura, para lo cual se plantean metas más específicas. En primer lugar, evaluar las ventajas de la economía circular frente al sistema convencional de gestión de recursos, la economía lineal, reconociendo los principios y metodologías del nuevo sistema.

Después, estudiar la situación actual global de esta nueva corriente para conocer sus principios, cuáles han sido los avances y qué iniciativas se han tomado hasta el momento para más tarde examinar su evolución en el entorno de la arquitectura.

El siguiente propósito será analizar la aplicación de la economía circular en el ámbito de la arquitectura en cuanto a procesos constructivos y sistemas de montaje empleados en casos reales y conocer sus límites.

Finalmente, se tratará de reconocer unos principios básicos y una metodología para la "arquitectura circular" con el fin de cumplir con el objetivo principal.

\section{Metodología}

Tras haber vivido una temporada en la capital chilena y haber visitado el pequeño pueblo de Chanco y su Museo de la Reconstrucción, un edificio fuertemente dañado por el terremoto que asedió la costa de ese país en el 2010, creció mi interés por la construcción con materiales reutilizados. Pero tras un período de indagación acerca de sostenibilidad, materiales reciclados y reutilizados y el respeto con el medioambiente, nació una pregunta: ¿hasta dónde se podría llegar con estos conceptos? Y la respuesta estaba en la denominada economía circular que se abordará desde el punto de vista de la arquitectura.

Para la primera aproximación al tema, y con el objeto de conocer a fondo en qué consiste la economía circular, se realizó una búsqueda genérica en la web y en diferentes bibliotecas. Entre el material hallado destaca el libro Cradle to Cradle: Remaking the Way We Make Things, páginas web como la de la Fundación Ellen MacArthur o la de la Comisión Europea y videos como TEDxLoodusele-Ken Webster-Circular Economy, información muy valiosa para poder reconocer los principios, objetivos y ventajas de la economía circular frente a la economía lineal.

Una vez conocido este nuevo modelo económico y su relación con la arquitectura, el siguiente paso a recorrer fue el análisis de casos reales. Para ello, primero se investigó la razón de ser de cada proyecto y su implantación. En segundo lugar, se hizo un análisis del sistema constructivo, el proceso de construcción y los materiales usados para cada parte del edificio y, por último, se realizó una pequeña reflexión sobre los resultados obtenidos. 
Para el estudio del Circular Building, la gran mayoría de la información se extrajo de la web de ARUP, la empresa encargada de su diseño y construcción, donde se puede encontrar toda la información detallada del proyecto. En cuanto al ICEhouse, se visitó la página web personal de William McDonough, arquitecto y autor del edificio, y la página web de su estudio, William McDonough + Partners. Respecto a los últimos casos, MicroHouse, Dashilar Pavilion y Fountainbridge Community Pavilion, toda la información se extrajo de la plataforma WikiHouse, donde se pueden encontrar todas las aclaraciones necesarias acerca de los proyectos relacionados con ella.

Realizada esta fase de indagación y análisis se procesó toda la información, se cruzaron datos, se discriminaron aquellos aspectos irrelevantes y se organizó el conocimiento adquirido con base en los objetivos establecidos para llegar, finalmente, a determinadas conclusiones.

\section{Antecedentes}

\section{La economía lineal como sistema de gestión convencional de los recursos en las sociedades capitalistas}

Desde la Revolución Industrial el sistema económico implantado en todo el mundo y especialmente en los países más desarrollados es el conocido como "economía lineal". Un sistema basado en la tríada comprar, usar y tirar, reflejo de una época en la que los recursos, la energía y el crédito parecían ser ilimitados y fáciles de obtener, una época en la que no había conciencia de las graves consecuencias medioambientales que este sistema podría llegar a ocasionar.

Sus principios son la extracción de materia prima, la producción y el consumo, lo que hace que solo funcione en una dirección, terminando cuando el consumidor desecha lo que no necesita o ya está obsoleto. Podría ser más larga o más corta, pero cada material solo tiene una "vida". Así se generan cantidades alarmantes de residuos y desechos en todo el mundo. En España, la cifra asciende a las 110518494 toneladas en el 2014, un 4,43 \% de toda la Unión Europea, de las que solamente el 33,3 \% fueron recicladas. $\mathrm{Al}$ año siguiente se produjeron, de media, 434 kilos de basura por persona en España y 476 en la UE, tratados de la siguiente manera:

\begin{tabular}{lcccc}
\hline \multicolumn{1}{c}{2015} & $\begin{array}{c}\text { Porcentaje } \\
\text { reciclado }\end{array}$ & $\begin{array}{c}\text { Porcentaje } \\
\text { incinerado }\end{array}$ & $\begin{array}{c}\text { Porcentaje } \\
\text { de compostaje }\end{array}$ & $\begin{array}{c}\text { Porcentaje } \\
\text { de vertederos }\end{array}$ \\
\hline Unión Europea & 28,57 & 26,47 & 16,39 & 25,63 \\
España & 16,82 & 11,52 & 16,36 & 55,07 \\
\hline
\end{tabular}

Como se puede observar en la tabla, especialmente en España, más de la mitad de los residuos generados por las personas son desechados y por lo tanto inservibles, mientras que tan solo un $16,82 \%$ de ellos, son objeto de procesos de reciclaje. Estas enormes cantidades de basura son un importante problema

Tabla 1

Tratamiento de la basura en España y la UE

Elaboración propia, con información de Europa.eu 
medioambiental que en algunas ciudades del mundo produce muchas enfermedades y graves problemas de salubridad para sus habitantes.

Pero esto es únicamente el resultado final del proceso. El gran problema nace realmente durante la producción; casi el $70 \%$ de los residuos se generan desde que se extrae la materia prima hasta que el producto llega a manos del consumidor, de los cuales gran parte son producidos para conseguir la energía necesaria para este proceso (Webster, 2012).

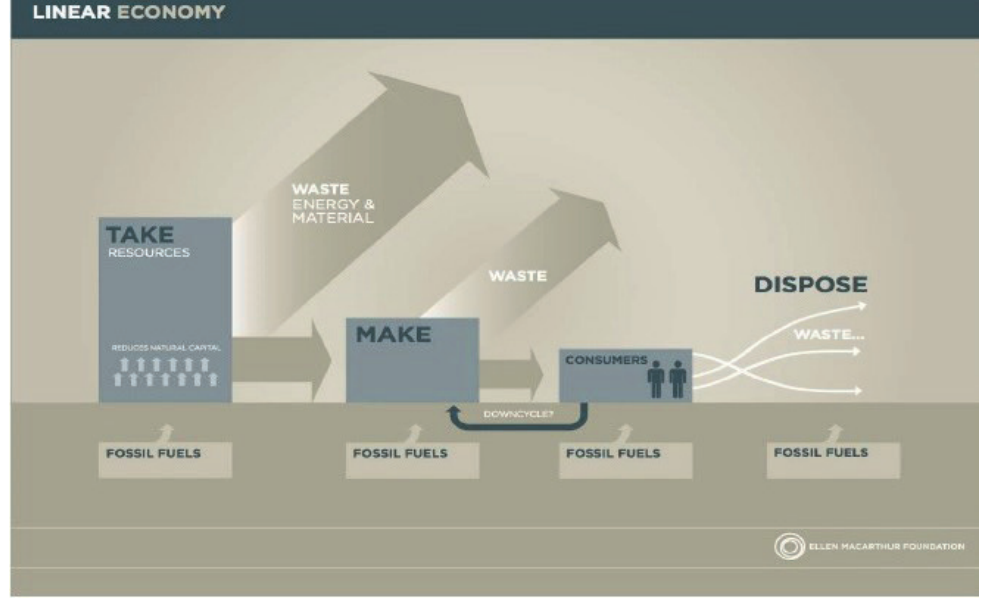

\section{Repercusión ambiental y reacción social: las cuatro erres}

El ritmo que lleva el sistema productivo a nivel mundial es frenético y devastador; ya se está hablando y avisando del problema desde hace mucho tiempo, pero se necesita de una solución rápida y eficaz. La cantidad de dióxido de carbono que hay en la atmósfera ha aumentado en un 30 \% desde la Revolución Industrial, lo que ha provocado que la temperatura global haya subido más de un grado. Parece que fuera un cambio insignificante, pero esto supone importantes consecuencias; los polos se derriten y en cien años el nivel del mar ha subido $17 \mathrm{~cm}$, a este ritmo, en 25 años podría subir otro grado más.

Predicciones de Naciones Unidas hablan de entre 50 y 200 millones de personas desplazadas a causa del cambio climático para el año 2050. Además, se producen 7 millones de muertes al año a causa de la contaminación atmosférica, el $12 \%$ de todos los fallecimientos, y, dentro de 25 años, el $5 \%$ de los animales podrían extinguirse (COTEC, 2017).

Los duros golpes que esto supone para el medioambiente y el planeta han generado, desde hace muchos años, la intención de frenar y reducir el ritmo de este proceso que no puede ser infinito. Por eso, se ha intentado concienciar a las 
personas sobre el reciclaje de forma continua e insistente. Así nació el concepto de las tres erres, "reducir, reutilizar y reciclar", al que más tarde se unió una cuarta, "recuperar". A continuación, una pequeña aclaración de los conceptos:

\section{Reducir}

- Consiste en evitar el uso de productos o materiales que realmente no son necesarios.

\section{Reutilizar}

- "Volver a utilizar algo, bien con la función que desempeñaba anteriormente o con otros fines" (Real Academia Española, 2014).

- "Utilizar de nuevo algo, a veces con funciones diferentes a las originales" (Larousse, 2016).

\section{Reciclar}

- "Someter un material usado a un proceso para que se pueda volver a utilizar" (Real Academia Española, 2014).

- "Someter un material de desecho a un proceso de transformación para reutilizarlo" (Larousse, 2016).

- "Reciclar es someter un material usado o un desperdicio a un proceso en el cual se recupera, total o parcialmente" (Significados, 2013-2017).

\section{Recuperar}

- "Volver a poner en servicio lo que ya estaba inservible" (Real Academia Española, 2014).

- Está más relacionado con los procesos industriales y consiste en volver a usar materiales o elementos que sirvan como materias primas.

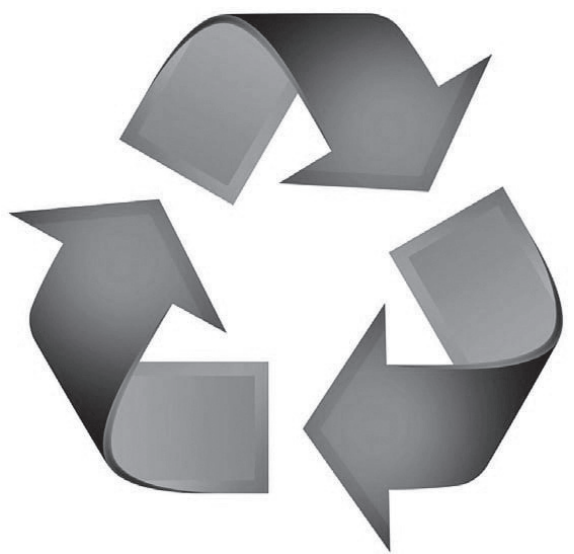

Figura 2.

Símbolo de reciclaje

Fuente:

PSD Graphics (2011) 
Es una muy buena iniciativa aplicar estos conceptos en el día a día y reducir la contaminación y los residuos, tanto por parte de las empresas como de los consumidores. Pero esto no soluciona el problema, tan solo consigue retrasarlo un poco y ralentizar el ciclo destructivo que, igualmente, algún día se convertiría en una situación insostenible para el planeta. Se siguen explotando los recursos naturales, se sigue produciendo a un ritmo frenético a la vez que se contamina y el consumo compulsivo no cesa. Como dijo uno de los grandes genios de la historia: "El mundo no puede evolucionar más allá de su actual situación de crisis utilizando el mismo pensamiento que creó esta situación".

De hecho, este sistema solo aplica soluciones al final del proceso; es decir, lo que se consigue es retrasar el mismo final, como así se dice en el libro Cradle to Cradle que se presentará más adelante:

Utilizamos soluciones de tipo "de final de tubo" para reducir al mínimo las disrupciones del sistema. Pero estamos descubriendo que las iniciativas que simplemente pretenden mejorar lo que estamos haciendo actualmente tienen resultados limitados. De hecho, podría resultar imposible que fuera ecológicamente sostenible lo que estamos haciendo actualmente. (Braungart y McDonough, 2005)

\section{Nuevas iniciativas en la gestión de recursos: economía circular}

El mundo tecnológico actual fue creado a partir de la Revolución Industrial del siglo XIX, pero respecto a su productividad y prosperidad, la economía moderna está repleta de errores y fallos que no fueron previstos en aquel entonces. Ahora, reducir, reutilizar o reciclar son conceptos que urgen a la gente concienciada con el medioambiente a hacer más con menos para reducir el impacto, pero los cimientos sobre los que se basa el sistema no fueron bien diseñados.

Alrededor del año 1970, cuando se comenzó a discutir acerca de las problemáticas con los residuos y el medioambiente, nació el término cradle to grave (de la cuna a la tumba), utilizado como reivindicación para acondicionar mejores lugares donde depositar la basura. Frente a esto, el arquitecto Walter R. Stahel reaccionó con el término cradle to cradle (de la cuna a la cuna) con la intención de hacer hincapié en que el vertedero debe ser el último recurso y la solución al problema era una economía en bucle o circular.

Más tarde, el químico alemán Michael Braungart y el arquitecto norteamericano William McDonough recuperaron el concepto del cradle to grave para hacer referencia a una consideración errónea de la naturaleza como una fuente inagotable de recursos, los cuales acaban destruidos y convertidos en basura inutilizable, un modelo económico que solo tiene un destino posible, la creación de tremendas cantidades de contaminación y residuos. Por lo contrario, ellos plantean un sistema en el que existan dos ciclos, el biológico y el tecnológico. El primero abarcaría todo lo que son productos para el consumo, que contienen nutrientes y materias biodegradables, de modo que, una vez terminada su vida útil, estas puedan ser devueltas a la naturaleza. El segundo contendría todo lo 
que son servicios, formados por "nutrientes tecnológicos" los cuales deberán ser desmontados y devueltos al ciclo productivo una y otra vez, infinitamente ("The Circular Economy: Interview with Walter Stahel", 2013).

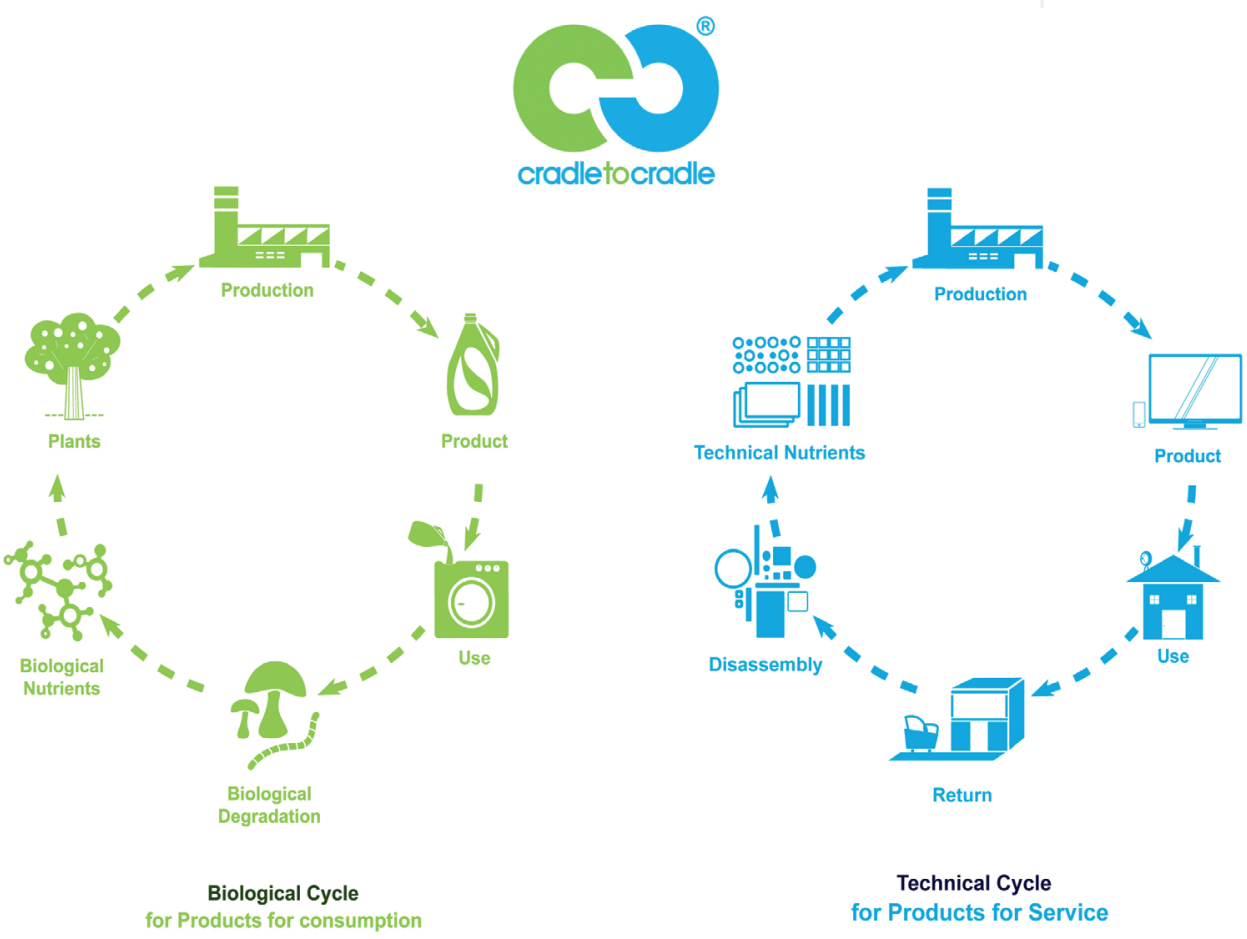

Ellos son los autores del libro Cradle to Cradle: Remaking the Way We Make Things que tiene como objetivo la explicación de las deficiencias del sistema actual frente a las posibilidades de una nueva concepción económica, la economía circular.

Figura 3.

Cradle to Cradle (C2C)

Fuente:

Cradle to Cradle (2013)

El concepto cradle to cradle, para ellos, nace de la naturaleza, haciendo una comparación con el mismo ciclo de esta en la que se intenta expresar que cualquier tipo de producto podría ser diseñado con el fin de que sus "residuos" pudieran servir de "alimento" para algún otro producto nuevo cuando su vida útil finalice. Es decir, concebirlas como nutrientes biológicos que circulan constantemente como materias valiosas dentro de un ciclo industrial cerrado en lugar de ser downcycled (término que se usa para referirse a una materia que es reciclada para formar parte de algún producto de peor calidad que el anterior). A esto lo denominan waste $=$ food $($ basura $=$ alimento), concepto que da nombre a uno de los capítulos del libro Cradle to Cradle. 
La naturaleza actúa según un sistema de nutrientes y metabolismos en el que no existe basura. Un cerezo fabrica muchas flores y frutos para que (tal vez) haya germinación y crecimiento. Por eso el árbol se cubre de flores. Pero las flores extra no son en absoluto inútiles. Caen al suelo, se descomponen, alimentan a varios organismos y microorganismos, y enriquecen la tierra. En todo el mundo, animales y humanos exhalamos dióxido de carbono que las plantas capturan y utilizan para su propio crecimiento. El nitrógeno residual es transformado en proteínas por microorganismos, animales y plantas. Los caballos comen hierba y producen excrementos, que proporcionan alojamiento y alimentación a las larvas de las moscas. Los principales nutrientes de la Tierra - el carbono, el hidrógeno, el oxígeno y el nitrógeno- entran en ciclos y son reciclados. Los desechos son alimento. (Backlight, 2013)

Los autores critican insistentemente el concepto de reciclaje tal y como es concebido hoy en día; piensan que solo sirve para crear productos de inferior calidad y retrasar su condición de basura final. Además, tienen muy claro que la sostenibilidad, como se trabaja en la actualidad, no es suficiente y hay que ir más allá.

Bueno, realmente no reciclamos productos, ese es el problema, los reciclamos para conseguir otro producto de peor calidad (downcycled products). (Backlight, 2013)

$[\ldots]$

Si nos fijamos en las botellas de plástico, tienen antimonio, un metal pesado cancerígeno, residuo de una reacción catalítica. Pues podríamos eliminar el antimonio y conseguir un producto de mayor calidad en lugar de usarlo para hacer un banco del parque, ensuciarlo con otros químicos y luego quemarlo. (Backlight, 2013)

[...]

Estamos buscando cosas que de verdad se puedan reciclar. Que vuelvan a su condición inicial o se puedan devolver al sistema de producción para formar parte de un producto de mayor calidad (upcycled). (Backlight, 2013)

[...]

El objetivo es muy simple y técnico, un mundo delicioso, diverso, seguro, sano y justo con aire limpio, un suelo limpio, agua limpia, energía limpia y económica, equitativa, ecológica y elegantemente disfrutado. (Backlight, 2013)

[...]

Sostenibilidad no es suficiente para nosotros porque si yo te preguntara, “¿Cómo va la relación con tu pareja?”, y tú me contestaras, "sostenible”, entonces te diría, "Oh Grob, lo siento por ti". Si esa es la clave, sostenibilidad, entonces es solo un mínimo, de alguna manera puedes lidiar con eso, es solo mantenimiento. (Backlight, 2013)

Esta manera innovadora de concebir los procesos de producción es la base de la economía circular en la que todo puede ser devuelto, de una u otra manera, de nuevo al ciclo y dejar de ser un sistema lineal en el que todo tiene un principio y un fin. Para ello, el Cradle to Cradle Products Innovation Institute 
ha creado una certificación de productos "Cradle to Cradle" $®$. Esta evalúa la seguridad del producto para el medioambiente y el diseño que tiene de cara a una vida futura. Se centra en el uso de materiales seguros que puedan ser desmontados y reciclados (como nutrientes técnicos) o desechados (como nutrientes biológicos). Además, los materiales usados y el proceso de fabricación de los productos se califican según estas cinco categorías:

- Salud del material: garantizar que todos los componentes químicos de los productos estén definidos como positivos y eliminar del proceso y reemplazar cualquier componente que esté clasificado como de riesgo alto o como no clasificable. Esta cualidad se juzga según un conjunto de criterios ambientales y de salud humana.

- Reutilización de materiales: se deben identificar los flujos de materiales que se pueden reutilizar cuando el producto se recupera después de haber sido usado por el usuario o el cliente. Los materiales se reutilizan como materias primas en el proceso de fabricación (tecnosfera) o como nutrientes biológicos (biosfera).

- Uso de energías renovables: uno de los tres principios más importantes de cradle to cradle es usar la energía solar actual, lo cual significa que ese uso de energía debe ser, en la mayor medida posible, renovable. De esta manera, las empresas garantizan que la mayoría de sus actividades y productos tengan un impacto positivo en el medioambiente y en la salud humana.

- Gestión del agua: las empresas que siguen este camino deben demostrar que están usando los recursos del agua de un modo responsable y ecoeficiente, y que los vertidos de las fábricas a los ríos locales sean de lo más limpios posible.

- Responsabilidad social: las empresas deben demostrar que cumplen con los más estrictos principios de responsabilidad en relación a su personal y deberán esforzarse en garantizar que las empresas de su cadena de suministro no estén violando estos principios.

Existen cinco tipos de certificación de los productos: base, bronce, plata, oro y platino. Se le adjudican, dependiendo de la calificación, que tenga un producto en las cinco categorías anteriores. Esto ayuda a muchas empresas a desarrollar sus productos de manera que cada vez sean menos perjudiciales para el medioambiente. Además, es aplicable a cualquier tipo de empresa, productos de limpieza, telas, maderas, jabones, pinturas carpinterías, moquetas, etcétera (Cradle to Cradle Products Innovation Institute, 2017).

Un ejemplo fantástico es el panel para acabados exteriores de madera de la empresa estadounidense Bark House. Es el único producto que ha obtenido el certificado platino de cradle to cradle. Se trata de unos paneles aplanados, secados al horno y recortados a medida, hechos de corteza de árbol recuperada. Un producto que cumple a la perfección los requisitos impuestos para este certificado (Bark House, 2017). 
Figura 4

Certified Cradle to

Cradle (C2C)

Fuente: Cradle to

Cradle Products

Innovation Institute

(2017)

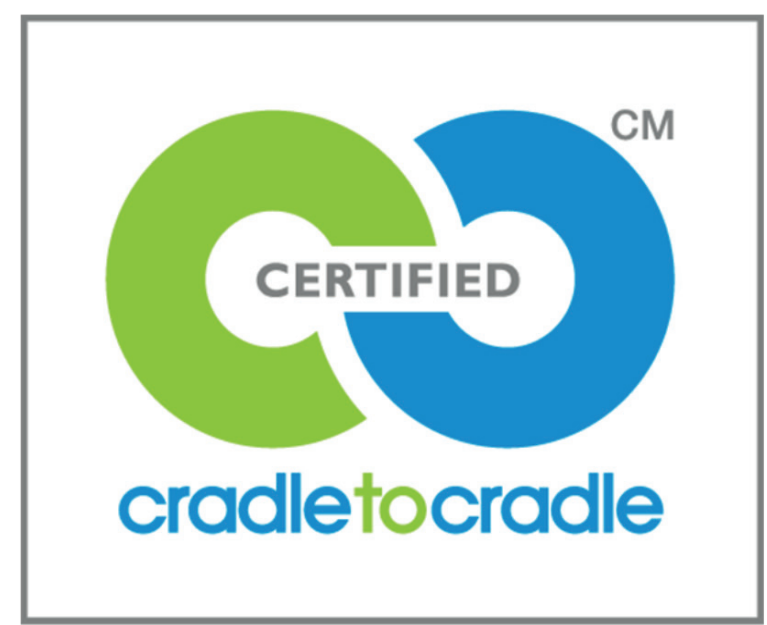

Otra pionera en el ámbito es Ellen MacArthur, exmarinera, emprendedora y conocida como la "Dama de la Economía Circular". Fue la impulsora de la Fundación Ellen MacArthur, organización benéfica que trabaja en las áreas de la educación, inspirando a nuevas generaciones para rediseñar el futuro, los negocios, trabajando en la innovación de las empresas y en la investigación para revolucionar el mundo del diseño.

La economía circular fue introducida a nivel europeo a partir de la influencia ejercida por la fundación, que logró que esta idea fuese aceptada totalmente por la Comisión Europea y las juntas directivas de grandes corporaciones multinacionales. Su visión de la economía circular también distingue entre ciclos técnicos y biológicos y es una economía reparadora y regenerativa, que pretende conseguir que los productos, componentes y recursos en general, mantengan su utilidad y valor en todo momento. Esta consiste en un ciclo continuo de desarrollo positivo y está basada en tres principios clave:

1. Preservar y mejorar el capital natural, controlando existencias finitas y equilibrando los flujos de recursos renovables.

2. Optimizar el uso de los recursos, rotando productos, componentes y materiales con la máxima utilidad en todo momento, tanto en los ciclos técnicos como en los biológicos.

3. Fomentar la eficacia del sistema, revelando y eliminando externalidades negativas.

Pero también distingue unas características fundamentales que describen lo que sería una economía estrictamente circular:

- Diseñar sin residuos: los residuos no existen cuando los componentes biológicos y técnicos de un producto se diseñan con el fin de 
adaptarse dentro de un ciclo de materiales biológicos o técnicos, y se diseñan para el desmontaje y la readaptación.

- Aumentar la resiliencia por medio de la diversidad: los sistemas diversos con muchas conexiones y escalas son más resilientes a los impactos externos que los sistemas construidos simplemente para maximizar la eficacia y el rendimiento con resultados de fragilidad extremos.

- Trabajar hacia un uso de energía de fuentes renovables: los sistemas deberían tratar de funcionar fundamentalmente a partir de energía renovable, lo que sería posible por los valores reducidos de energía que precisa una economía circular restaurativa.

- Pensar en "sistemas": la capacidad de comprender cómo influyen entre sí las partes dentro de un todo y la relación del todo con las partes, resulta fundamental.

- Pensar en cascadas: para los materiales biológicos, la esencia de la creación de valor consiste en la oportunidad de extraer valor adicional de productos y materiales mediante su paso en cascada por otras aplicaciones (Ellen MacArthur Foundation, 2017).

Desde la Fundación Ellen MacArthur crearon un esquema explicativo, dibujado por McDonough y Braungart, donde se pueden ver los ciclos biológicos y tecnológicos y la trayectoria que tomaría cada producto en una economía perfectamente circular.

Un buen ejemplo sobre el ciclo biológico sería la madera. Después de ser obtenida de un árbol, esta podría ser usada, por ejemplo, para hacer un revestimiento de chapas de madera. Sus procesos de "cascada" podrían ser, en primer lugar, un aglomerado de partículas de madera y luego un producto hecho con fibras. Finalmente, si durante alguno de estos procesos se le ha añadido algún químico, este puede ser extraído de ella y usado para generar biogás o ser devuelto a la biosfera.

Un caso dentro del ciclo tecnológico podría ser una lavadora. En caso de que se estropeara, sería reparada y devuelta a su uso con normalidad. Una vez el primer usuario ya no la necesitara, podría ser reutilizada por otro. Si termina su vida útil y se vuelve inoperativa, puede ser devuelta al lugar donde fue fabricada y desmontada para usar sus piezas de nuevo en otra lavadora, o bien para ser recicladas con el fin de obtener de nuevo los materiales que conformaban dichas piezas.

La economía circular es un sistema que engloba a cualquier tipo de industria, desde la que hace caramelos hasta la que construye grandes aviones. Abarca cualquier parte del proceso, desde el consumidor hasta la empresa más grande. Incluye cualquier etapa del proceso productivo, desde que se planta un árbol para la extracción de la madera como materia prima hasta que esta, después de haber sido reutilizada y reciclada, vuelve al suelo de donde nació para ser 
Figura 5

Esquema de la

economía

Fuente:

Ellen MacArthur

Foundation (2017) nutriente de otro nuevo árbol. Puede ser aplicada a la industria textil, alimentaria, informática, robótica, automovilística, etcétera. Pero el sector en el que se centra este trabajo es el de la arquitectura, un campo en el que todavía hay mucho camino por recorrer.

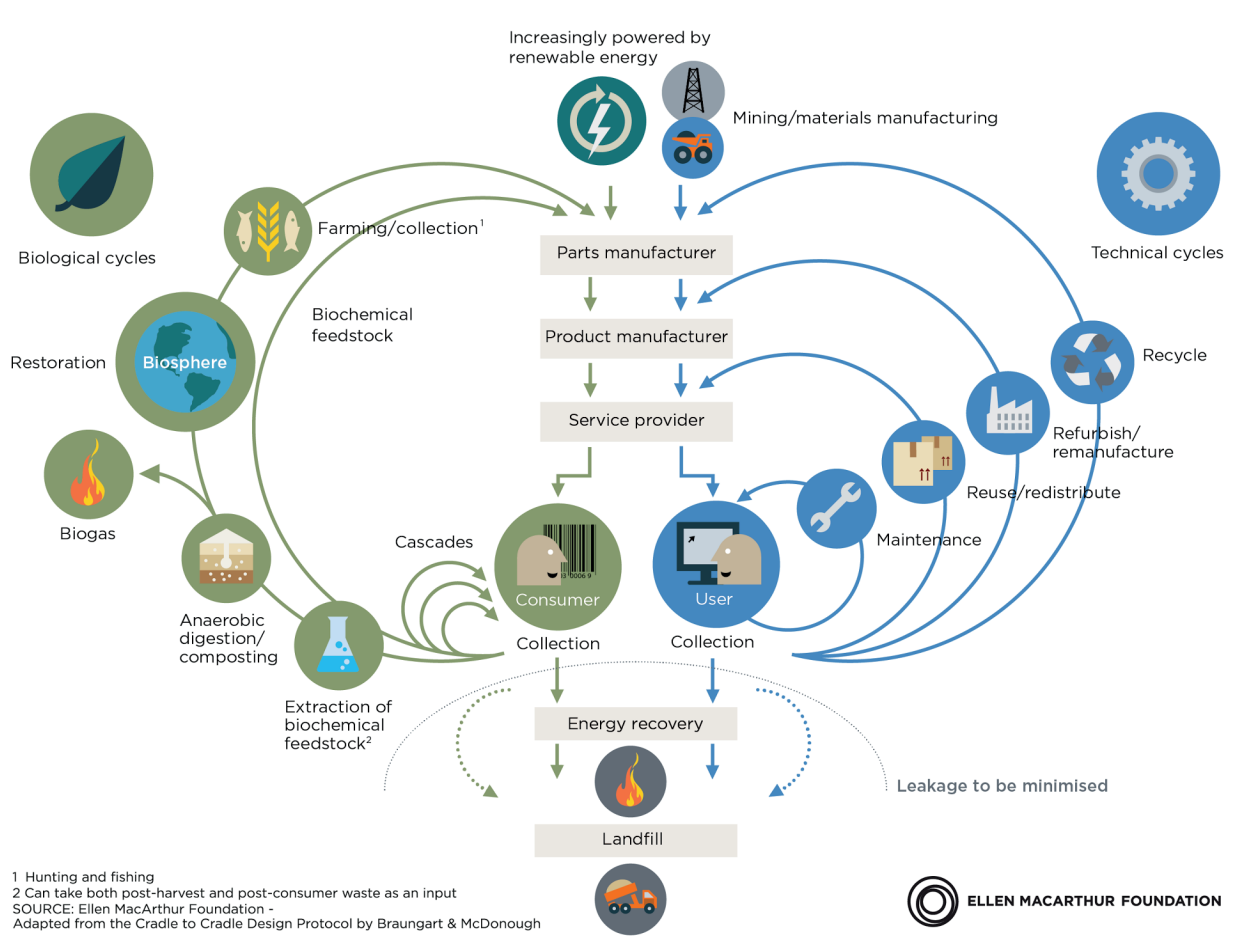

\section{LA ECONOMÍA CIRCULAR APLICADA A LA ARQUITECTURA}

\section{Arquitectura circular: definición y principios}

Hace ya mucho tiempo que escuchamos los términos "sostenibilidad", "eficiencia energética", "arquitectura sostenible", etcétera, pero la sociedad avanza muy rápido y con ella el sector de la construcción y la arquitectura. Estos conceptos, que hace muy poco tiempo eran novedosos y avanzados, ya quedan demasiado desgastados y usados, muchas veces erróneamente. Una vez que los consumos y las emisiones de los edificios son reducidos al mínimo, la siguiente meta es el impacto sobre el medioambiente que hay más allá del edificio. La energía consumida, los recursos necesarios y los residuos que produce la industria de la construcción también deben ser regulados. 
Hoy en día, la mejor manera de actuar de forma sostenible es aplicando el concepto de la economía circular a la arquitectura, de ahí el título "arquitectura circular", que en otros sectores de la industria ya se utiliza con más frecuencia. Ya no sirve simplemente reciclar o usar materiales reciclados. La idea es ir más allá y rediseñar las cosas teniendo en cuenta que, al finalizar su vida útil, estas puedan ser desmontadas o despiezadas y aprovechadas en un futuro. El problema es que se siguen construyendo edificios según unas necesidades para un tiempo indefinido, bonitos y funcionales en el contexto actual, pero no se suele pensar que así lo será durante toda su vida útil, si será habitado o no, o si cumplirá siempre la misma función. También se usan materiales con una caducidad diferente (madera, acero, hormigón, plásticos, etcétera) sin tener en cuenta si con el paso de los años el edificio tendrá que ser rehabilitado, rediseñado o demolido y, en caso de serlo, cómo sería ese proceso. Pero entonces surge una pregunta: ¿sería factible diseñar un edificio en el cual todos los componentes que lo forman pudieran ser reutilizados, reciclados o refabricados al concluir su vida útil?

Bien, es un reto complicado, pero se puede trabajar en ello. Para empezar, desde el punto de vista circular, se debe diseñar mediante sistemas funcionales, es decir, teniendo en cuenta la adaptabilidad y modularidad de todas sus partes y también el posible cambio de necesidades a lo largo de su vida. Esto permitiría enfrentarse a cada problema desde diferentes puntos de vista y ofreciendo nuevas posibilidades de uso y reutilización. Además, es indiscutible la importancia del diseño de un proyecto, pero también es crucial la implicación de las empresas proveedoras y la relación entre ambas partes, ya que el proceso de proyección debe ir de la mano con la adquisición de los materiales para poder prever su montaje, interacción, adaptación, comportamiento y desmontaje.

Existe un concepto llamado shearing layers, pensado por Stewart Brand, que organiza los edificios en diferentes grupos: parcela, estructura, envolvente, instalaciones, espacio interior y mobiliario. Evidentemente, la vida de cada una de estas partes puede variar muchísimo, por lo que no pueden ser tratadas igual, pero sí han de estar coordinados entre sí.

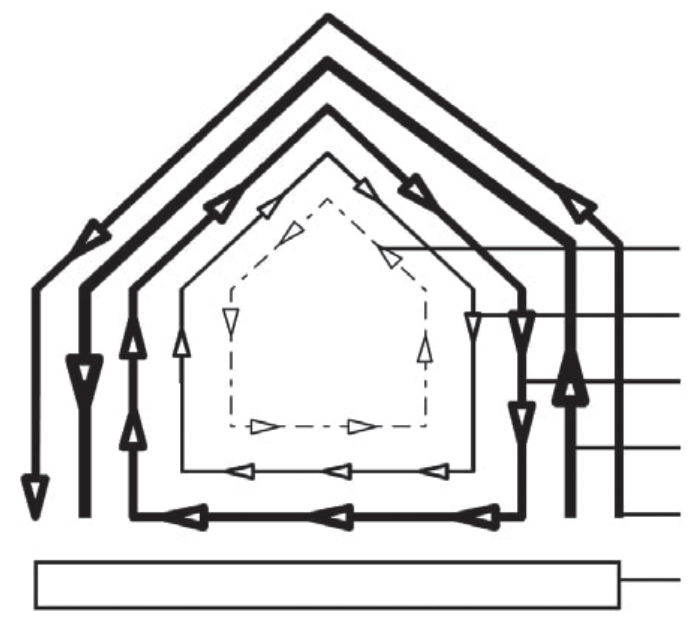


Trabajar de esta manera permite mejorar mucho la interacción entre las diferentes partes y conseguir la concordancia y el fácil mantenimiento a lo largo de la vida útil del edificio. Pero todavía no se ha encontrado ningún edificio "perfectamente circular", aunque aplicando estas premisas, considerando temas como el uso de materiales reutilizables, reciclables o refabricables, admirando la posibilidad de alquilar como alternativa a la compra u optando por la fabricación seca en taller con ensamblajes mecánicos en lugar de adhesivos in situ para facilitar el desmontaje, entre otras cosas, se puede acercar poco a poco al objetivo.

En la arquitectura convencional se trabaja de manera similar, pero una vez construido el inmueble, en gran parte de los casos, la única manera de deshacerlo es a través de la demolición. En este caso también existe un trabajo de coherencia entre las partes, pero muchas de ellas quedan unidas sin una vuelta atrás; en cambio, en la arquitectura circular cada elemento es independiente, teniendo la gran ventaja de que un edificio pueda ser desmantelado y todas sus partes aprovechadas de nuevo. Además, el objetivo es que cada una de ellas sea $100 \%$ reutilizable y reciclable según los principios de la economía circular y obviamente, en la medida de lo posible, respetar las máximas medidas de sostenibilidad en cuanto a eficiencia energética. Esto mejoraría cuantiosamente la calidad de un edificio y su respeto al medioambiente y con la salud del planeta.

\section{IDENTIFICACIÓN Y ANÁLISIS DE CASOS}

En este apartado del trabajo se procede a recoger información y analizar una serie de proyectos que se considera que cumplen con los principios de la "arquitectura circular". Se han descartado para el análisis proyectos muy interesantes como el EcoCubo, la Waste House o la Upcycled House, considerando que están formados en gran parte por materiales reciclados o reutilizados, pero no están pensados para ser "circulares", es decir, no están diseñados para poder ser introducidos de nuevo en el ciclo.

\section{Circular Building}

Circular Building es un prototipo, un experimento, un reto en el que se pone a prueba la aplicación de la economía circular en la industria de la construcción. El desafío consiste en construir un edificio donde, al final de su vida útil, todos sus componentes puedan ser reutilizados, reciclados o refabricados; en definitiva, poder darle otra vida sin producir ningún desperdicio. Para ello, la metodología empleada se basa en el análisis de los impactos ambientales de los productos utilizados durante su fabricación, diseño, construcción, mantenimiento y fin de su vida útil, llegando incluso al análisis de su composición química.

El diseño es de ARUP Associates con la colaboración de Frener \& Reifer, BAM y The Built Environment Trust. Ellos, junto a los proveedores, se vieron obligados a pensar y rediseñar de manera diferente los materiales y procesos de construcción. Fue construido en Londres para el London Design Festival 
2016 y su función fue la de albergar un espacio en el que se realizarían tours informativos acerca del pensamiento circular de la economía aplicada a la construcción y la realización de conferencias también relacionadas con el mismo tema. Se mantuvo abierto al público desde el 19 de septiembre hasta el 6 de octubre de 2016, cuando fue totalmente deconstruido.

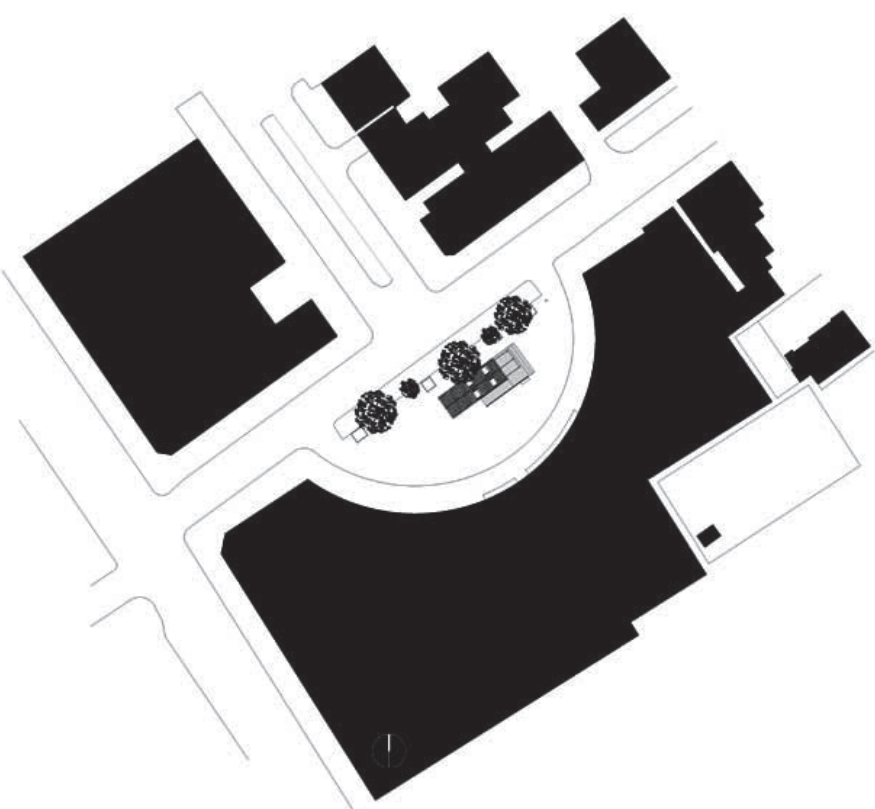

Figura 7. Circular

Building (plano)

\section{Fuente:}

Arquitectura + Acero (2016)

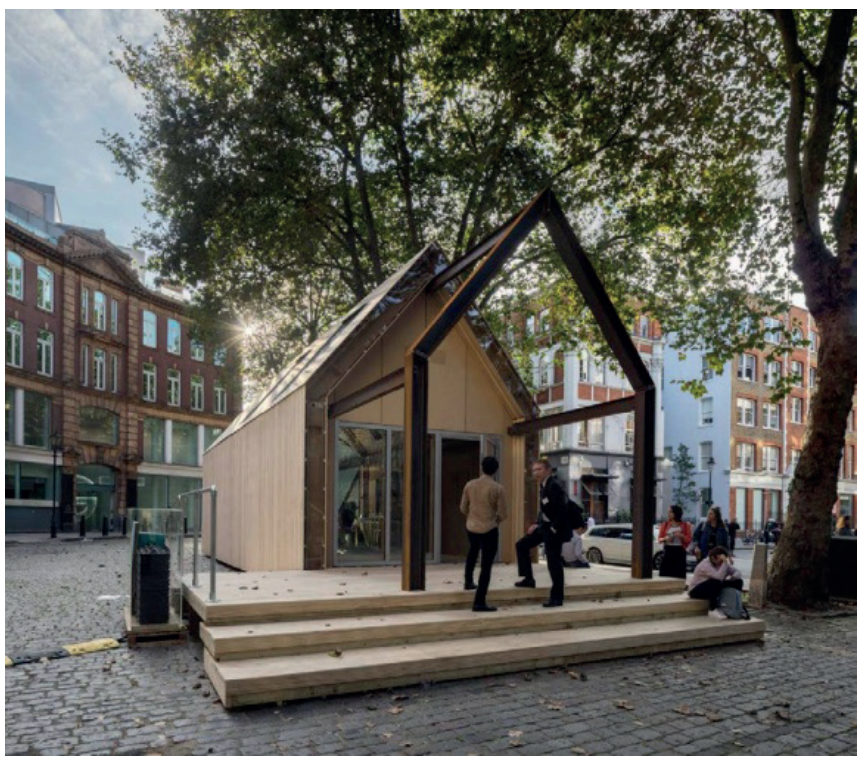

Figura 8.

Circular Building

Fuente:

Arup (2021) 
Estuvo situado justo enfrente de The Building Center, una organización desarrollada para promover la innovación en el entorno de la construcción. La dirección es Store Street 26, Bloomsbury, Londres, muy cerca del Museo Británico (The British Museum). Las coordenadas GPS exactas son $51^{\circ} 31^{\prime}$ 9.97” N (latitud) y $0^{\circ} 7$ '55.38” O (longitud).

\section{Análisis constructivo}

Los elementos principales del sistema estructural del Circular Building son pórticos de acero a dos aguas hechos de recortes de otros proyectos a los que el edificio tuvo que ajustarse por las longitudes de acero disponibles. Los perfiles se unieron mediante un sistema mecánico que permite su fácil desmontaje para que, una vez terminada su vida útil, pudieran ser devueltos al proveedor para ser reciclados o en el mejor de los casos reutilizados. Durante el proceso de reciclaje, los subproductos que aparecen pueden ser utilizados como materias primas en otras industrias como el cemento, fertilizantes o combustibles para aviones.

En cuanto a la unión entre estas vigas, se usaron unos sistemas de acero diseñados específicamente para fijar elementos sin necesidad de agujerearlos, formados por placas, tornillos y tuercas de acero para fijar las vigas entre sí o a otros materiales como la envolvente de madera. Las piezas las facilitó la empresa Lindapter.

Para la subestructura del suelo, se tanteó la opción de obtener viguetas de madera recuperada, incluyendo el uso de maderas victorianas que en ese momento se estaban eliminando de otro sitio en Londres, pero, finalmente, estas opciones no fueron factibles. La madera de abeto utilizada fue cosechada y fabricada en Suecia, suministrada con certificación PEFC de bosques bien gestionados de acuerdo a criterios de sostenibilidad. Respecto a su uso posterior, no hay rutas de reutilización establecidas para la madera tratada y el reciclaje es incluso problemático, pero el grupo Travis Perkins Group, proveedor del material, quiso aprender participando en el proyecto y examinó la idoneidad de la madera para su reutilización. En el peor caso, recuperarían la energía de las maderas como parte de la red de reciclaje y recuperación establecida.

La envolvente del edificio estaba formada por paneles de madera con cuatro tipos diferentes de aislamiento para probar su rendimiento. En la cara interior se colocaron unos paneles acústicos en una de las zonas y en la cara exterior de los paneles membranas impermeables y un revestimiento de madera laminada.

Dichos paneles se hacen a partir de desperdicios agrícolas y colas naturales con mejores propiedades estructurales e ignífugas que las alternativas de madera. Se montan in situ mediante un sistema de machihembrado de las piezas para su fácil desmontaje. Respecto a los aislantes, el primero está formado por aerogel, un producto novedoso que goza de una conductividad térmica muy baja y es transpirable y resistente al agua, propiedades ideales para un aislante. 
El segundo de ellos es un aislante creado con residuos agrícolas combinados con micelio, el "pegamento de la naturaleza" para hacer productos libres de formaldehído, seguros, saludables y sostenibles, además de poder ser usados como abono al final. El tercero es un aislante de lana de roca y por último es el llamado Inno-Therm, hecho de tela vaquera y algodón en un $80 \%$, todos ellos reutilizables y reciclables.

Los paneles acústicos del revestimiento interior, que se colocaron únicamente en una zona, se fabrican a partir de polietileno tereftalato (PET) reciclado al transformarse botellas de plástico en estos paneles.

En cuanto a la cara exterior de los paneles de madera, se colocaron primero las membranas impermeables, hechas a partir de policloruro de vinilo (PVC) reciclado, transpirables y adheridas al cerramiento mediante arandelas y tornillos de manera que se puedan recoger de nuevo. Encima de ellas se puso el acabado de madera laminada, procedente de bosques controlados y sostenibles, tratada de manera que pueda ser reciclada.

Los últimos componentes de la envolvente son las claraboyas. Tienen un rendimiento energético excepcional y una esperanza de vida de treinta años, además no utilizan adhesivos en su fabricación ni en su instalación y tienen un fácil desmontaje y reciclaje. Sus respectivos vidrios están hechos sin recubrimiento que permite su reciclaje sin introducir impurezas en el ciclo del material.

En relación con las instalaciones, la eléctrica se alimenta de unas baterías que funcionan a base de agua salada y no contienen metales pesados ni productos químicos tóxicos, tampoco son inflamables ni explosivas. Son las únicas que tienen el certificado Cradle to Cradle. Las lámparas están hechas de vidrio reciclado de jarras y pensadas para ser desmontadas y recicladas de nuevo. Respecto al sistema de ventilación, es mecánico y está diseñado y construido con una impresora 3D con PET de botellas reciclado al $90 \%$, el resto son aluminio reciclado y plexiglás. Para los conductos se utiliza cartón y un recubrimiento de cartulina, ambos materiales provenientes de bosques gestionados y sostenibles.

Para el equipamiento interior se utiliza una moqueta de la empresa Desso, ya nombrada en el trabajo, de la cual al menos el $70 \%$ de su contenido es reciclado y tiene el certificado Cradle to Cradle. Los sillones, BuzziNordic, están hechos $100 \%$ de residuos de botellas de plástico reciclado. Los aparatos electrónicos están proporcionados por la empresa Re-Tek que se encarga de restablecer y reparar aparatos electrónicos para hacer posible su reutilización y reducir la emisión de dos mil toneladas de $\mathrm{CO}_{2}$ al año. Por último, las sillas Moss del fabricante OrangeBox, diseñadas para poder ser desmontadas y recicladas al final de su vida útil. 


\section{Conclusiones}

Es realmente sorprendente ver cómo en este proyecto del Circular Building se trata tan al detalle la "circularidad" de los materiales componentes. Entre todos, tanto diseñadores como proveedores, trabajan codo con codo para conseguir así la máxima aplicabilidad de la economía circular. La gran mayoría de los materiales de construcción son reciclados y algunos nuevos, pero todos se pueden reutilizar después de su uso y muchos pueden ser vueltos a reciclar.

Es muy importante también que el edificio pueda ser desmontado al $100 \%$, cada pieza y cada elemento, de la misma manera en la que llegó al montaje y así respetar el concepto de circularidad. Es un muy buen ejemplo para tener en cuenta la forma en que se podría aplicar este concepto en la realidad y hasta qué punto se puede llegar hoy en día.

De todas maneras, esto fue tan solo un experimento, un edificio de planta baja, de tamaño reducido y uso temporal. Seguramente, el proceso sería bastante más complicado si se tratara de un edificio de grandes dimensiones y para un uso que requiera de unas características especiales o más complicadas. Aun así, no cabe duda de que es un gran avance en el sector y un gran ejemplo a seguir.

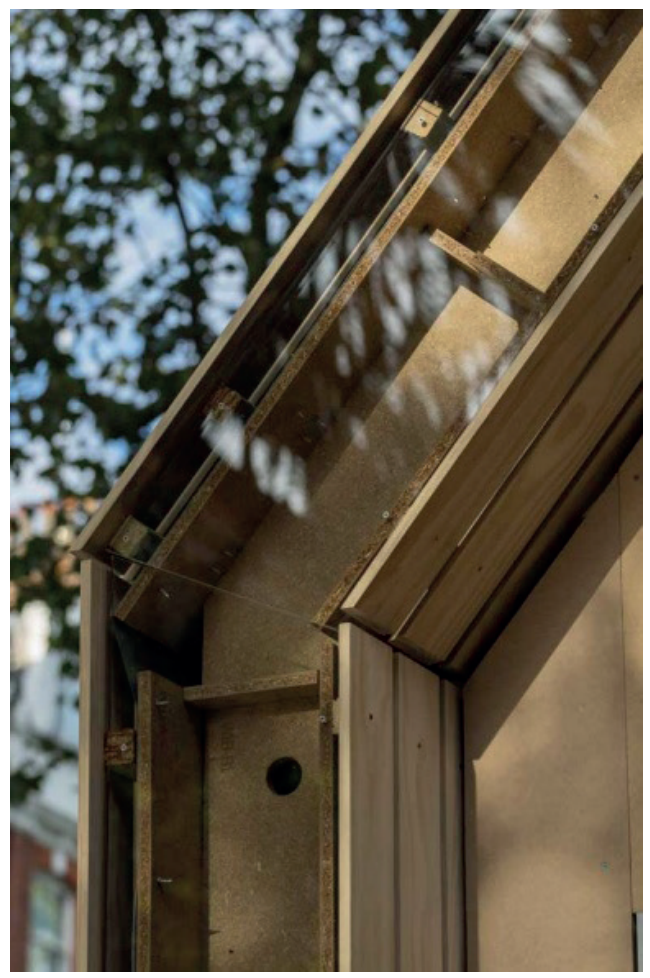




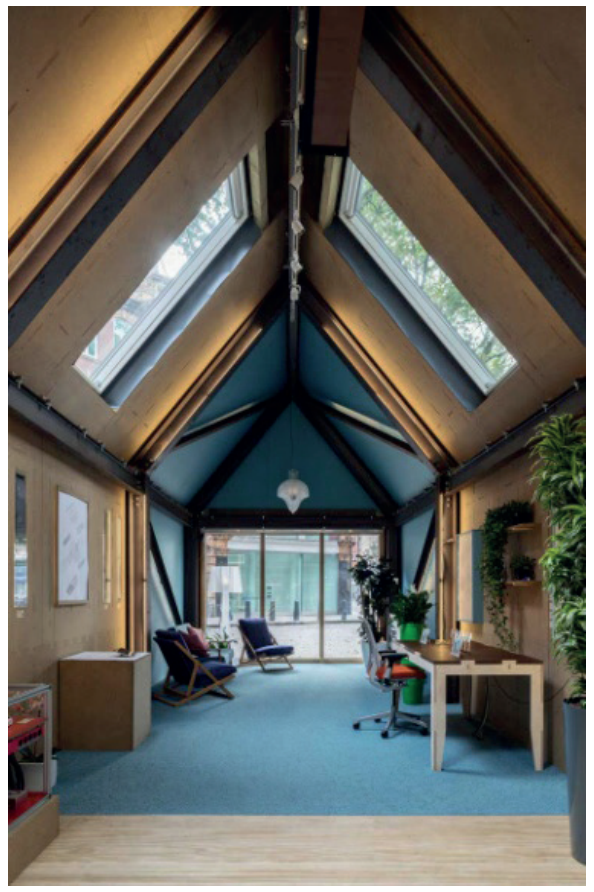

Figura 10.

Circular Building

Fuente: Arup (2021)

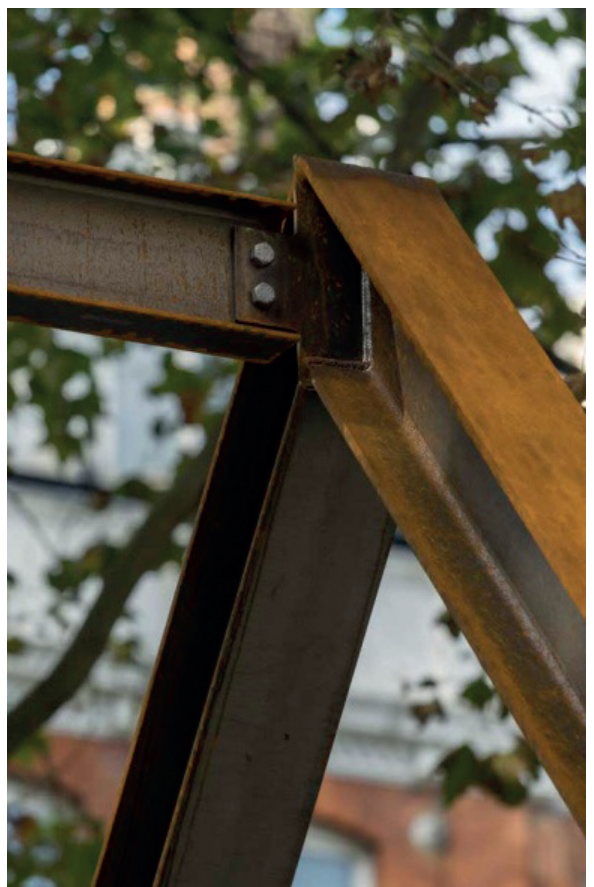

Figura 11

Circular Building

Fuente: Arup (2021) 
Figura 12

Circular Building

Fuente: Arup (2021)

Figura 13

Circular Building

Fuente: Arup (2021)
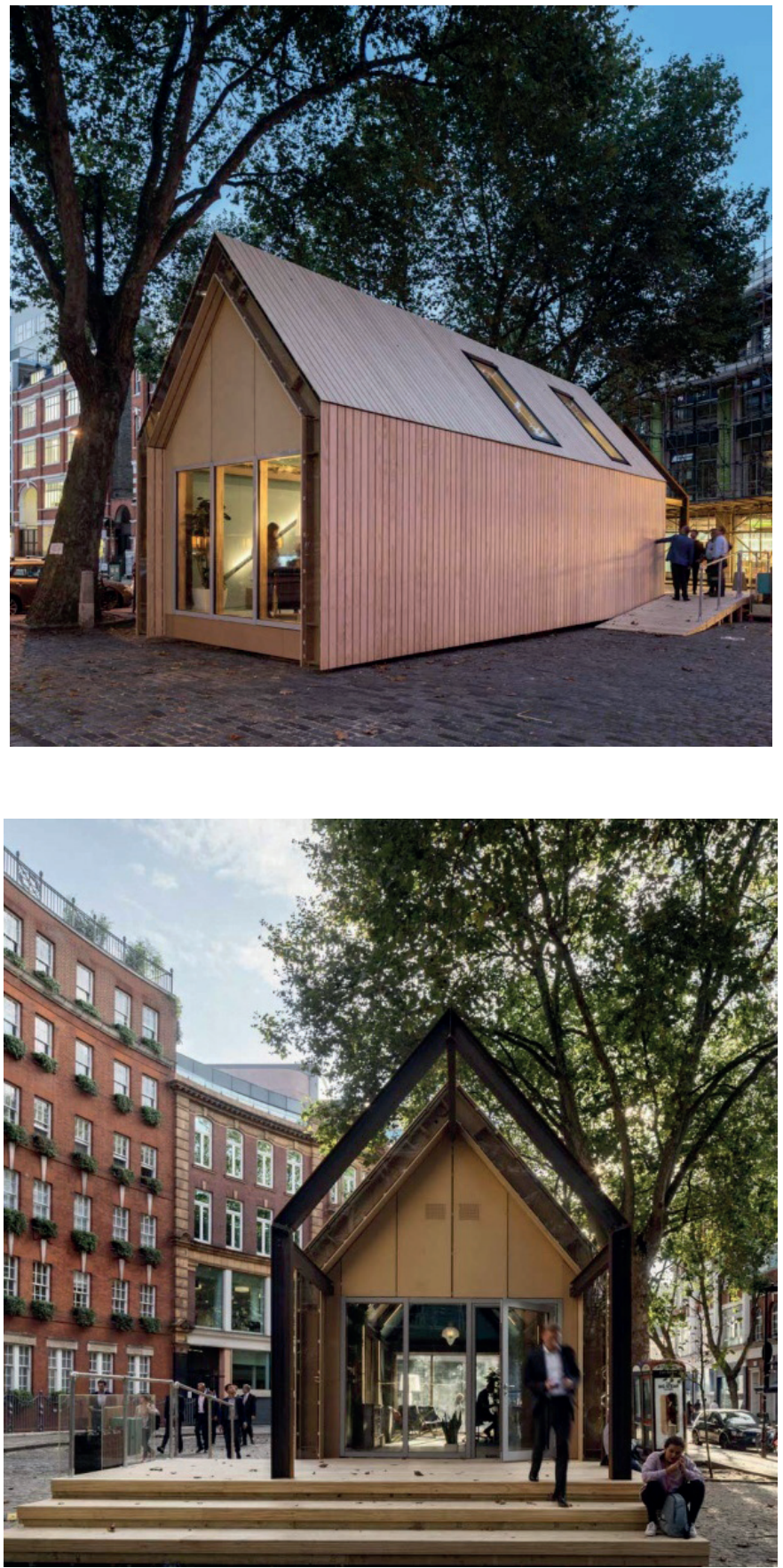


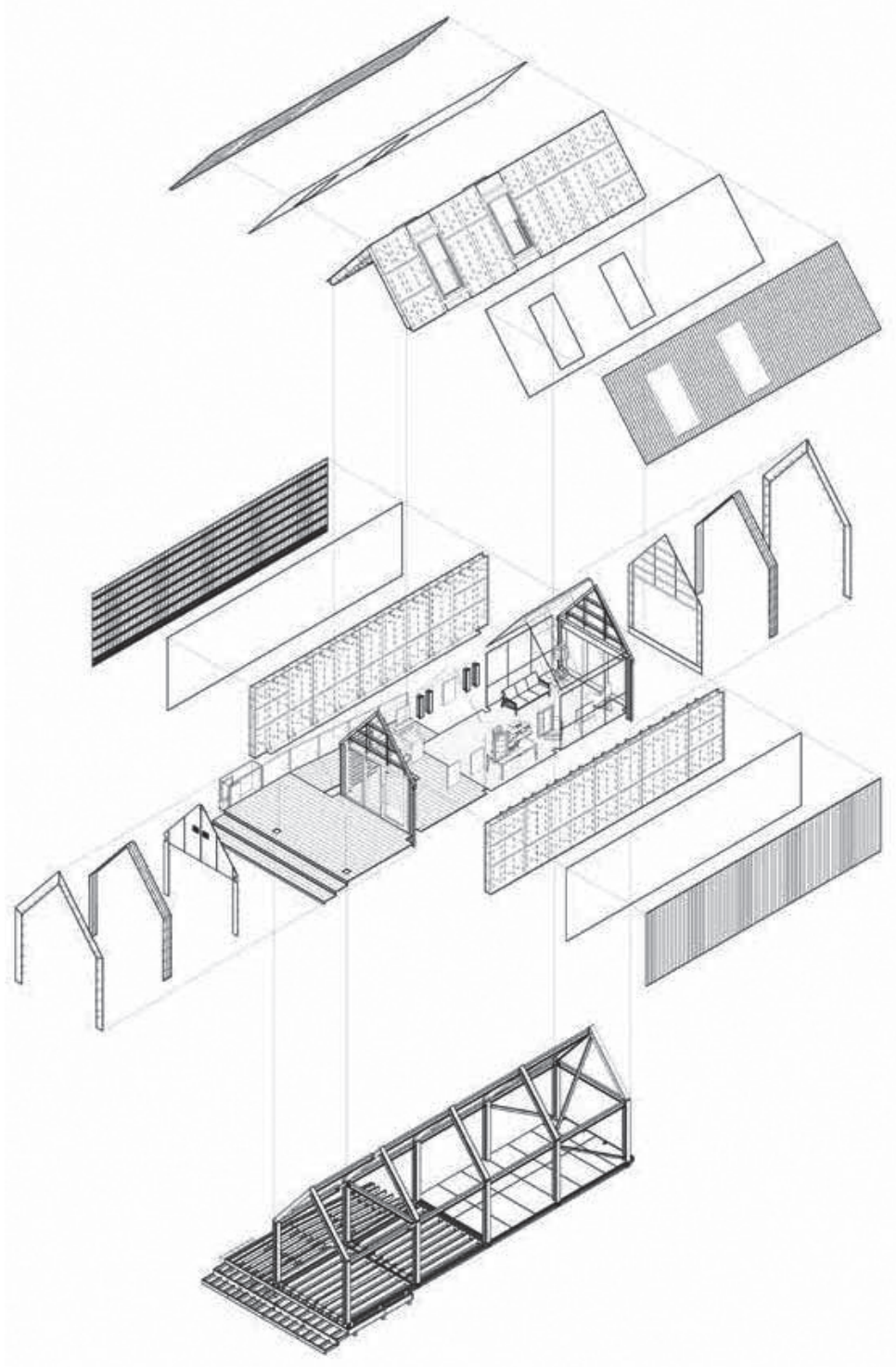

Figura 14.

Circular Building (plano)

Fuente:

Arquitectura + Acero (2016) 
Figura 15. Circular Building (plano)

Fuente: Arquitectura + Acero (2016)

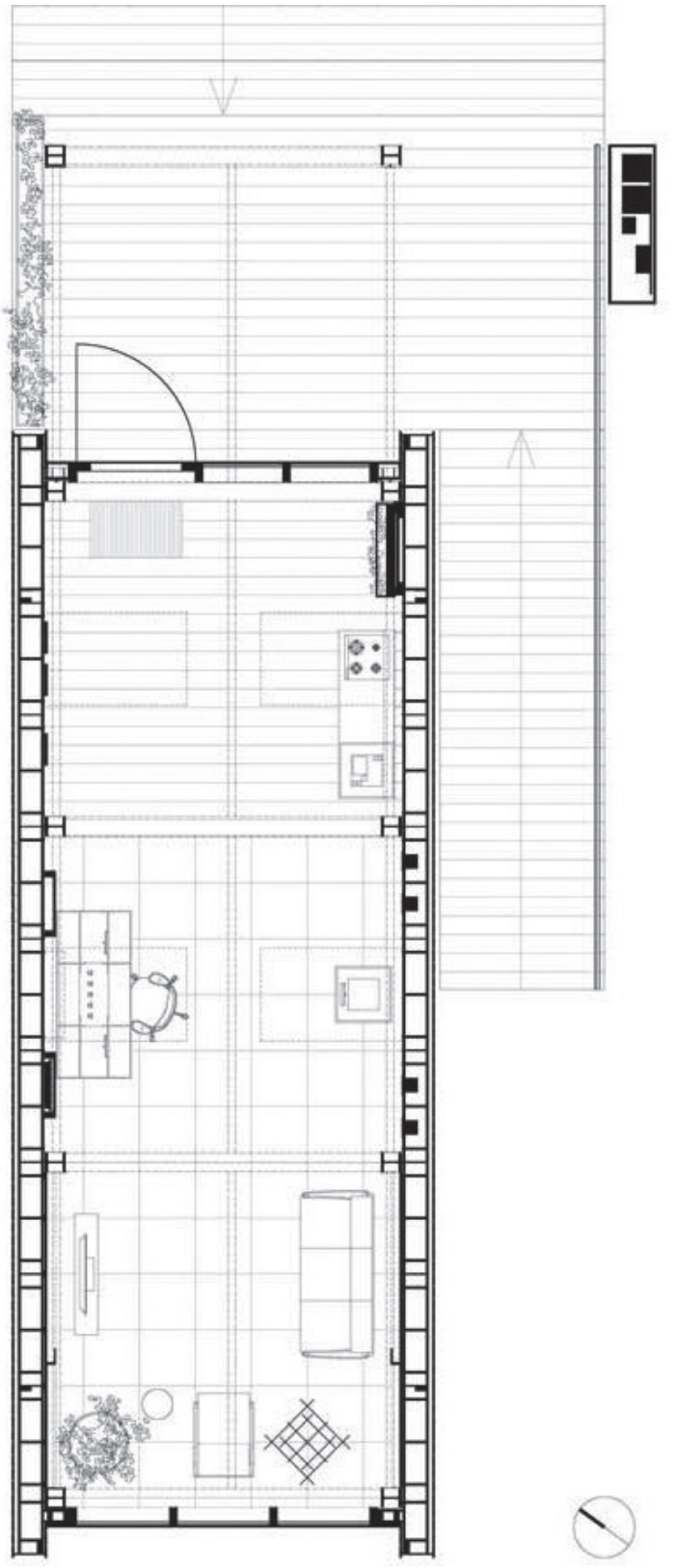




\section{ICEhouse}

ICEhouse es un prototipo experimental construido en enero de 2016 para los asistentes de la reunión anual del Foro Económico Mundial en Davos (Suiza), con el objetivo de discutir el futuro de la innovación en la economía circular. Fue diseñado por William McDonough + Partners y construido por WonderFrame LLC, con la colaboración de SABIC y SAP.

Su nombre es un juego de palabras, ya que por un lado "ICE" es el acrónimo de "Innovation for the Circular Economy" y, por otro, significa hielo. Explica el autor:

ICEhouse es una estructura diseñada para ser desmontada y reconstruida. En un sentido poético, como el hielo, ICEhouse es efímero: está aquí una semana, en los Alpes. La semana que viene se derretirá... destinado a aparecer en otro lugar. (William McDonough, 2016)

El edificio fue construido en nueve días y hecho para demostrar el diseño positivo descrito en el libro Cradle to Cradle, los objetivos de desarrollo sostenible de las Naciones Unidas y la reutilización de los recursos implícitos en la economía circular. Según su diseñador:

Creo que lo realmente apasionante para mí es que fuéramos capaces de construirlo en siete días y la semana siguiente sea transportado a Ámsterdam. Es un edificio que demuestra los conceptos del Cradle to Cradle donde los residuos se convierten en "comida", es decir, se convierte en un edificio útil una y otra vez y nunca terminará en un vertedero, nunca, es nutrición para el ciclo tecnológico. Esto me emociona, pero también me emociona que delante de la asombrosa audiencia que hay en Davos, podamos mostrar una estrategia que realmente proporciona un nuevo sistema de construcción que puede ser útil para gente necesitada alrededor del mundo, para billones de personas. (William McDonough, 2016, p. 28)

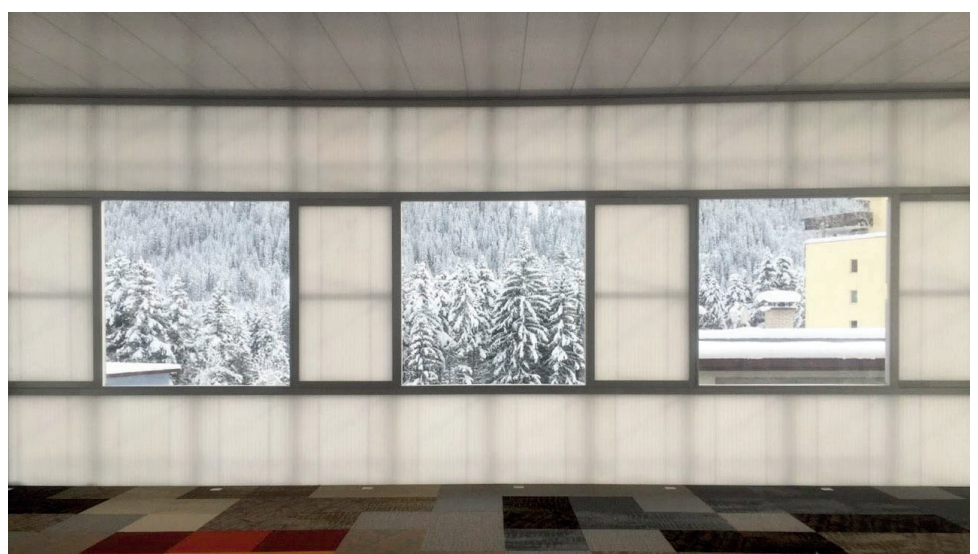


Figura 17 ICEhouse

Figura 18

ICEhouse

Fuente:

Roberts (2016)

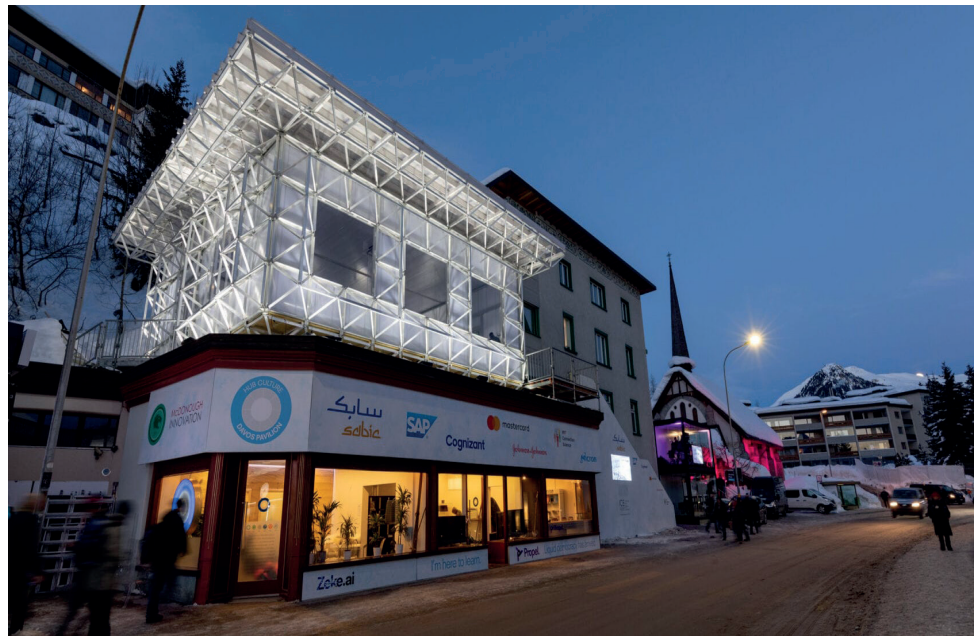

Este edificio, así como el Circular Building, tiene la peculiaridad de poder ser desmontado y vuelto a montar en otro lugar, adaptándose a las condiciones meteorológicas. Su primera localización fue en Davos, un pueblo suizo en plena cordillera de los Alpes. Su dirección exacta fue Promenade 93, 7270 Davos Platz y sus coordenadas GPS $46^{\circ} 48^{\prime} 4.68^{\prime \prime} \mathrm{N}$ (latitud) y $9^{\circ} 49^{\prime} 41.60^{\prime \prime}$ E (longitud).

En abril de 2016, el ICEhouse se reconstruyó en The Valley, Schiphol Trade Park en Ámsterdam, la ubicación del nuevo National Hub para la economía circular, diseño del cual todavía está en desarrollo y McDonough es el principal arquitecto. Es un lugar todavía ocupado por campo, justo al lado de la estación de tren de Hoofddorp y sus coordenadas GPS aproximadas son $52^{\circ}$ $16^{\prime} 58.80^{\prime \prime} \mathrm{N}$ (latitud) y 4 $41^{\prime} 47.64^{\prime \prime} \mathrm{E}$ (longitud).

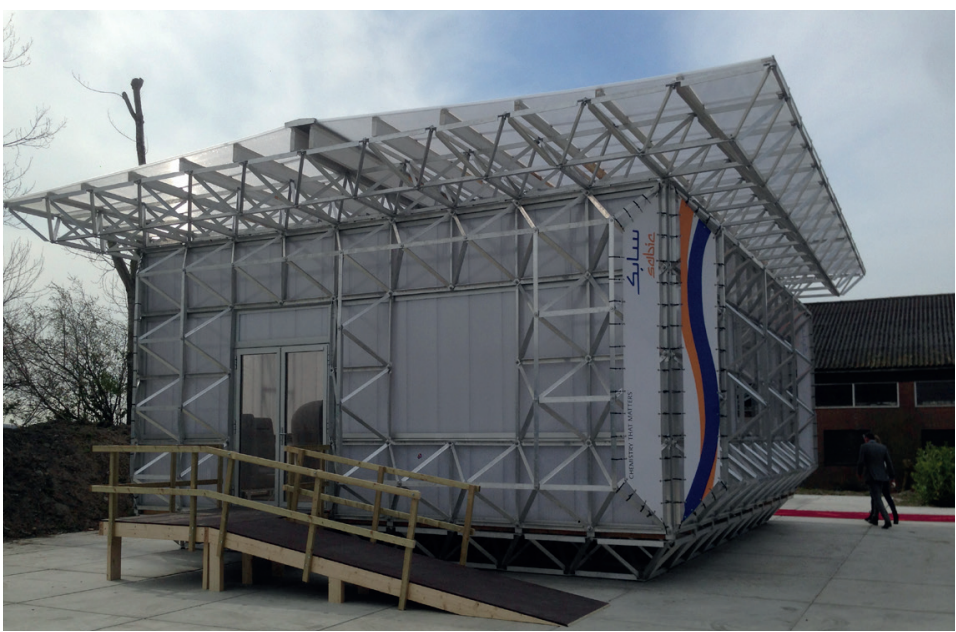




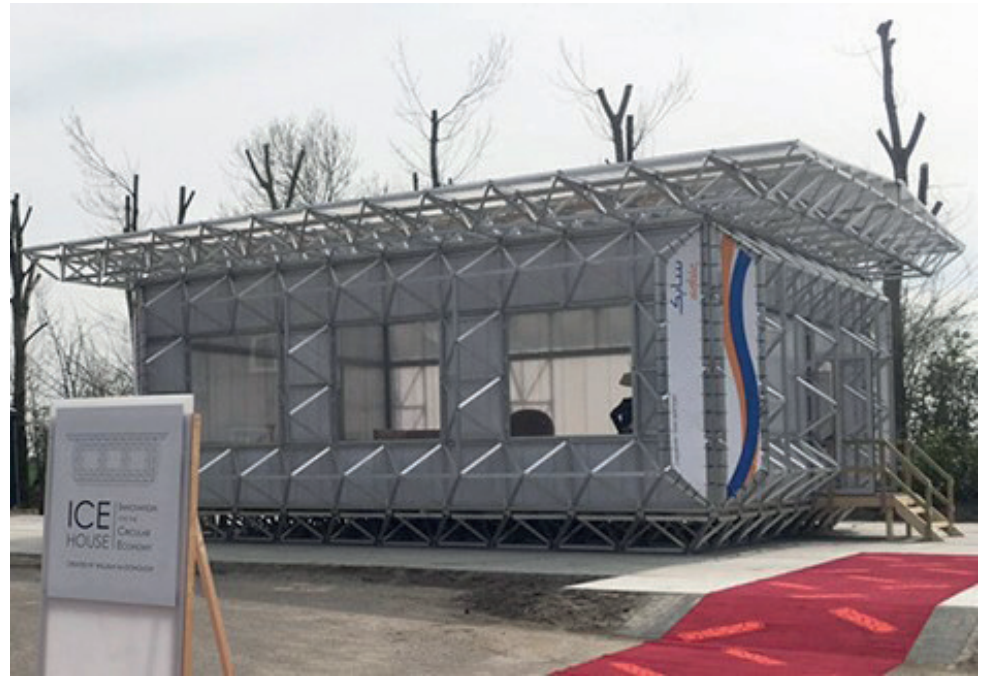

\section{Análisis constructivo}

Está compuesto por una estructura triangulada formada por perfiles angulares de aluminio unidos mediante pernos. El objetivo de este sistema es que pueda ser construido por cualquier persona con sus propias manos y dos llaves inglesas. Es un experimento en el empleo del WonderFrame, diseño de William McDonough en busca de un sistema estructural simple y flexible que podría levantarse rápidamente con materiales locales y adaptarse a una variedad de usos. Se sigue investigando para usar otras materias primas como plásticos o bambú.

En cuanto a la envolvente, tanto las paredes como el techo están formados por paneles de policarbonato LEXAN, de la empresa SABIC. Estos paneles contienen un aislante en su interior, el primero hecho de nanogel y con la certificación Cradle to Cradle.

Finalmente, respecto a las instalaciones y el equipamiento, todas las luminarias del edificio están hechas de policarbonato, así como los muebles que hay en el interior, ofrecido por la empresa italiana Kartell. En cuanto a la moqueta del suelo, está hecha de nylon 6 y fabricada por la empresa Patcraft.

\section{Conclusiones}

Como se puede observar, el edificio está construido de manera que pueda ser fácilmente desmontable para poder ser vuelto a construir y hecho en su totalidad por cuatro materiales: aluminio, policarbonato, nanogel y nylon 6. Además, definidos como "nutrientes técnicos", al final de su ciclo de uso estos materiales serán devueltos a la industria y refabricados sin fin en nuevos productos sin 
Figura 20. ICEhouse

Fuente: Roberts (2016)

Figura 21

ICEhouse

Fuente: Roberts (2016) que el material pierda su calidad. Todos los materiales tienen la certificación Cradle to Cradle o están en proceso de obtenerla. Sin duda, este prototipo es un ejemplo brillante de arquitectura circular pensado desde el principio para tener una vida "infinita”.
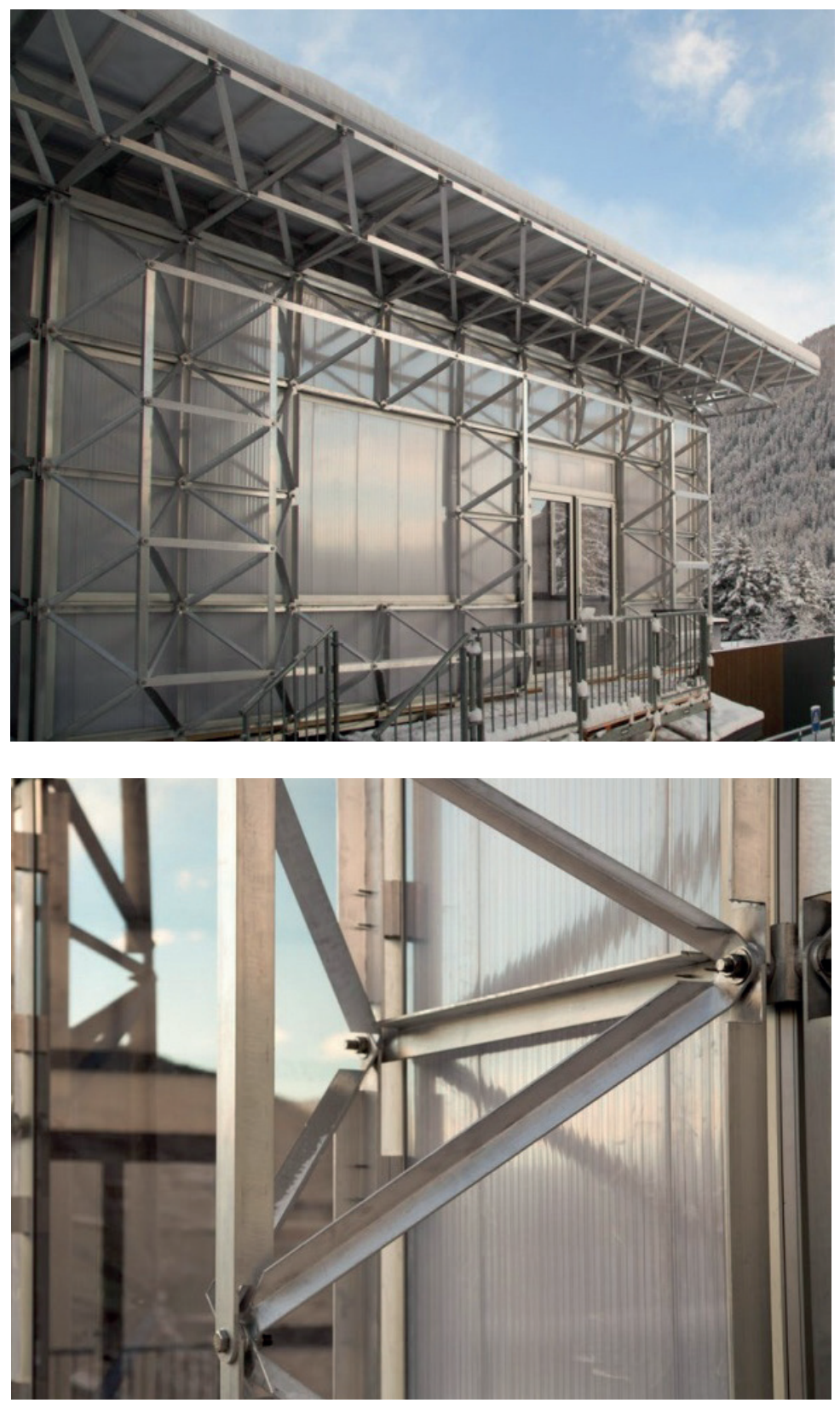


\section{MicroHouse}

WikiHouse, una fundación con sede en Reino Unido, tiene un modelo "beta" estándar de un diseño pensado para adaptarse a diferentes usuarios y lugares, el llamado MicroHouse, todavía en desarrollo. Un modelo muy simple y básico que contiene una habitación, un baño y un salón-cocina en una superficie construida de $37,5 \mathrm{~m}^{2}$. En la misma web se puede descargar gratuitamente toda la información acerca del modelo, planos CAD de sus piezas, tanto estructurales como de mobiliario, un manual de montaje y un archivo Excel con todas las especificaciones de los materiales ideales para el montaje. El precio total del modelo oscila entre los 42000 y 50000 euros.

Desde el mismo manual de montaje, se advierte al consumidor que es un modelo todavía en desarrollo y no se garantiza su perfecto funcionamiento. Además, se recomienda contactar con un especialista de la construcción, ya que los cimientos no están incluidos y es imprescindible su empleo adaptándose al lugar y las condiciones finales del edificio y, por supuesto, para cumplir la normativa legal vigente de cada lugar.

\section{Análisis constructivo}

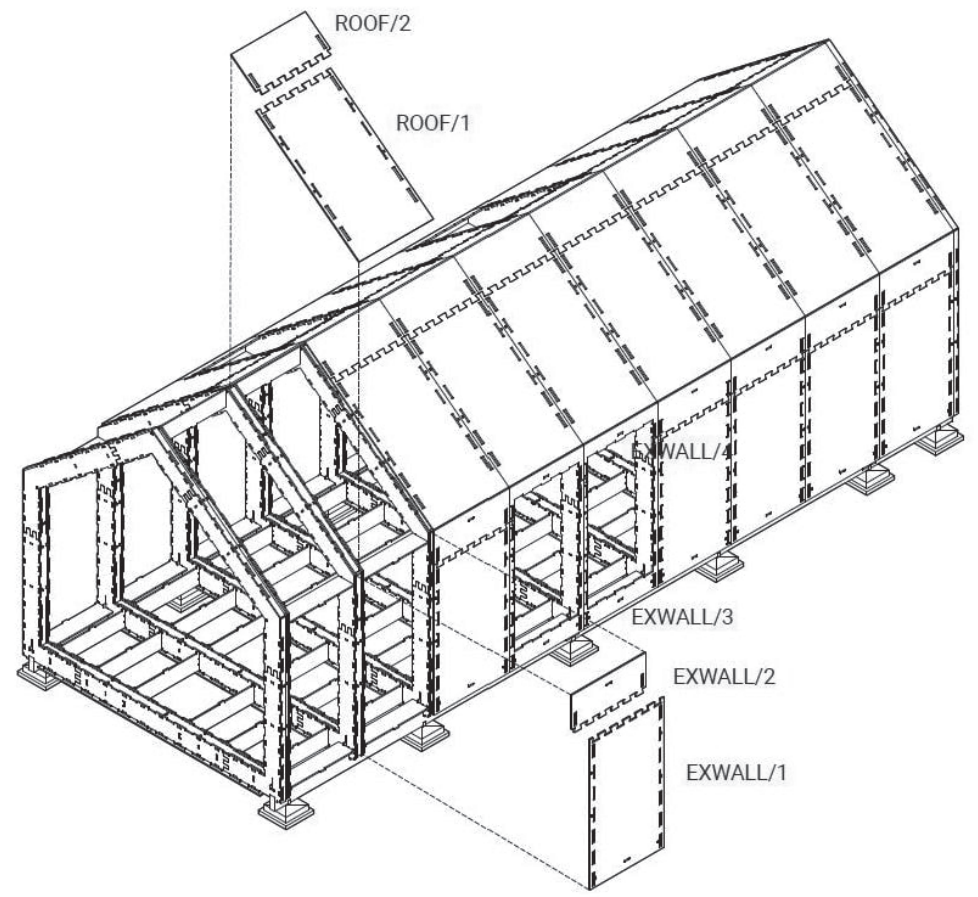

Figura 22. Imagen 1

Fuente: WikiHouse (2017) 
Figura 23. Imagen 2
La estructura principal del modelo está formada por diez pórticos de madera contrachapada de $18 \mathrm{~mm}$ de espesor, rellenos de aislante de poliestireno extruido, con cubierta a dos aguas y separados entre sí a una distancia aproximada de $1 \mathrm{~m}$, para más tarde colocar una serie de planchas de las mismas características en las paredes y el techo formando la envolvente, que también va rellena de aislante.

En la cara exterior de la envolvente va colocada la membrana impermeabilizante y un revestimiento de placas metálicas recubiertas de PVC, atornilladas a unos listones con sección en forma de cruz que a su vez van colocados encima de la membrana y encajados sobre los pórticos, tanto en las paredes como en el tejado.

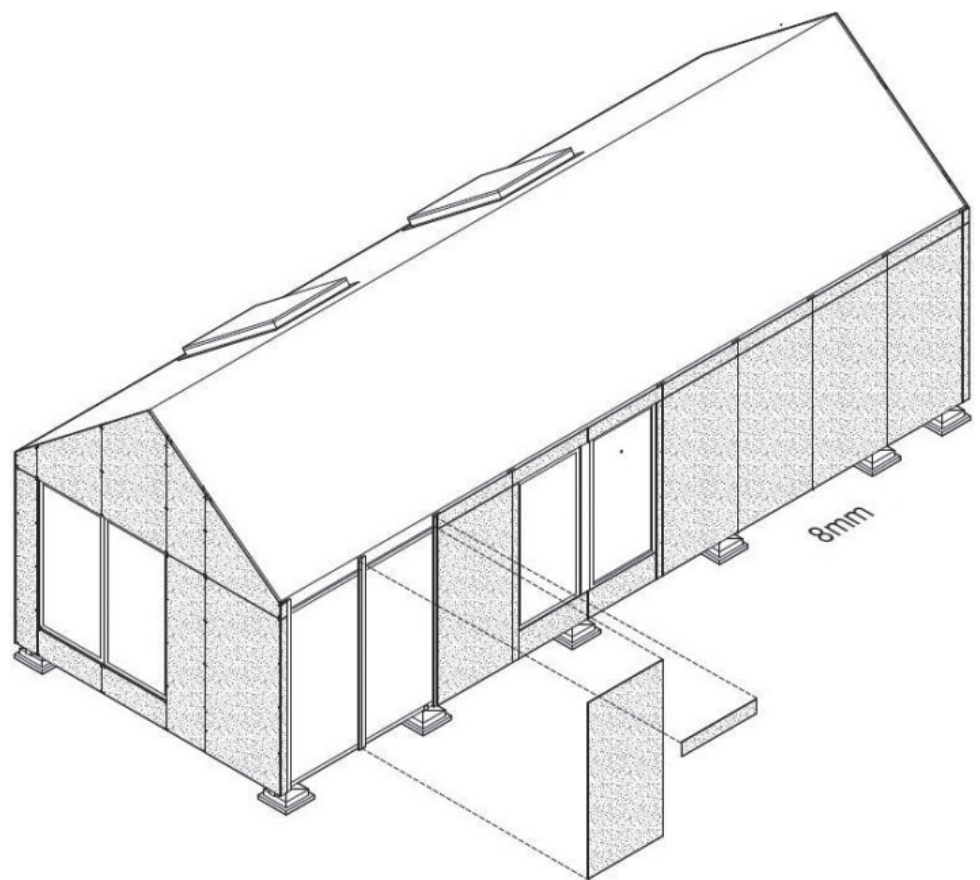

El sistema está perfectamente modulado, por lo que las puertas y ventanas se pueden cambiar de lugar, así como su composición y modelo, dependiendo de lo que haya al alcance en cada lugar en concreto. Esto ocurre también para los elementos y materiales del resto de la casa como acabados interiores, instalación eléctrica, fontanería, elementos sanitarios, algunos elementos de mobiliario, etcétera.

\section{Conclusiones}

Es un modelo hecho por y para todo el que lo quiera, por lo que cada persona puede seguir los pasos hasta el punto que crea conveniente, ya que es totalmente 
modificable y personalizable. Además, al estar estructurado con un sistema de piezas machihembradas y unidas mediante sistemas mecánicos, puede ser desmontado y reutilizado o reciclado, dependiendo de los materiales y productos que use el consumidor. Podría convertirse en el primer hogar de la "arquitectura circular".

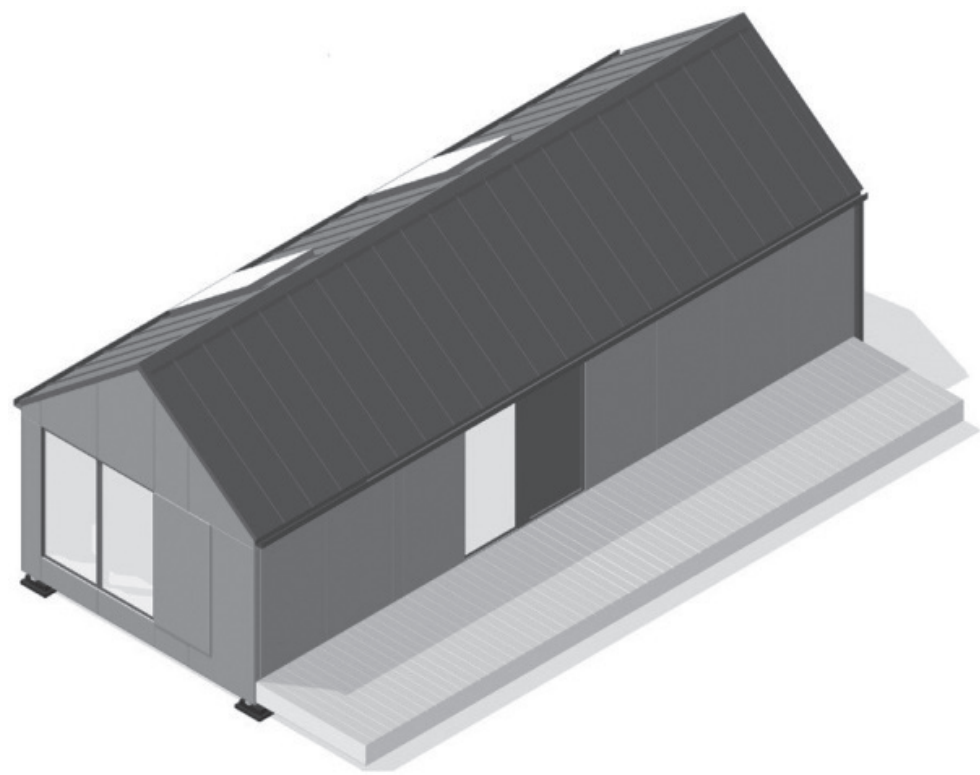

Figura 24.

Microhouse_0.5_isoFull

Fuente: WikiHouse

(2017)

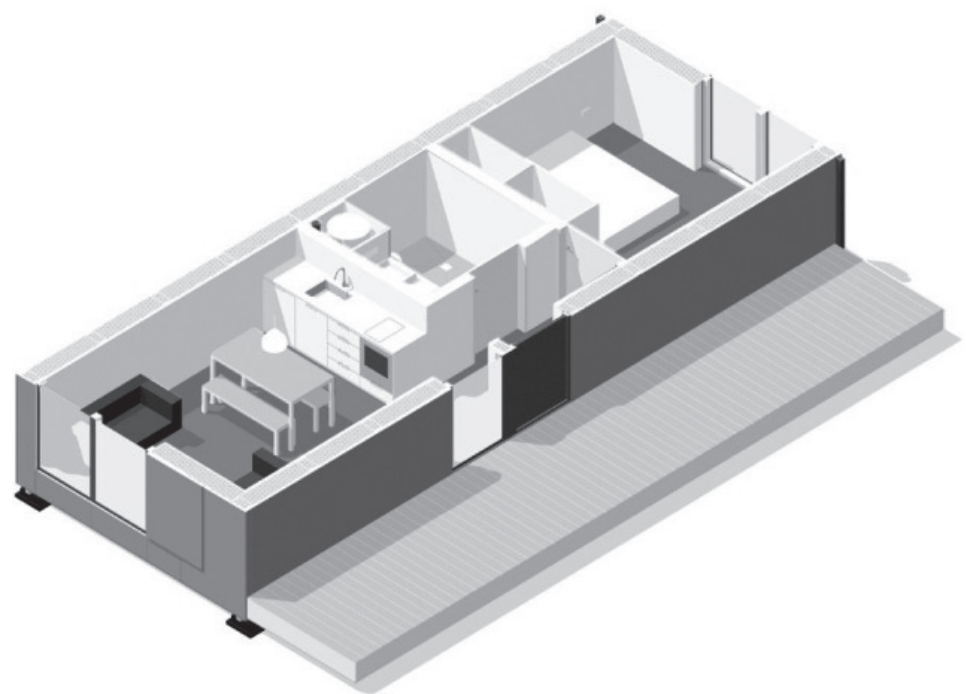

Figura 25.

Microhouse_0.5_isoFull

Fuente: WikiHouse (2017) 


\section{Dashilar Pavilion}

Este prototipo fue construido en Dashilar, en la ciudad de Beijing, en un instituto de secundaria para el Beijing Design Week en octubre de 2016. Fue diseñado por DotMake y construido en solamente siete horas por doce alumnos de secundaria.

\section{Análisis constructivo}

Está basado en el sistema estructural de WikiHouse, pero se modificó el tamaño y la altura del pabellón de acuerdo con las condiciones del sitio y, teniendo en cuenta que iba a ser construido por niños, se buscó un material que no fuera tan pesado como el original contrachapado de madera. El material elegido fue PVC de alta densidad, ya que no necesita recubrimiento y es bastante más ligero. Dado que el pabellón era una estructura temporal, se redujo la sección de los elementos estructurales y el aislamiento térmico fue reemplazado por bancos de madera prefabricados. Finalmente, para el techo, se usaron hojas de policarbonato huecas y translúcidas.

\section{Conclusiones}

El proceso de ensamblaje demostró perfectamente la eficacia del sistema WikiHouse. Como contribución al proyecto de código abierto, DotMake subió los dibujos y compartió la experiencia con la comunidad para ayudar a otros equipos a desarrollar aún más su propia versión del proyecto. Finalmente, este proyecto está formado solamente por tres materiales, PVC de alta densidad, madera y policarbonato $y$, aunque no se conoce la utilidad que se les dio después de su uso para el Beijing Design Week 2016, se sabe que es perfectamente desmontable y todas sus piezas reutilizables y reciclables, por lo que cumpliría con los principios de la "arquitectura circular".

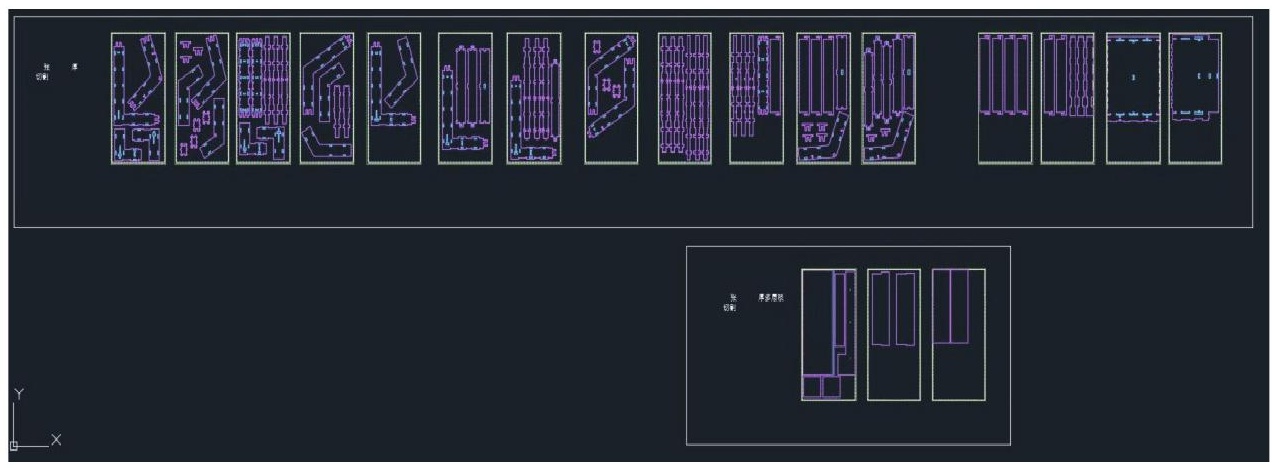



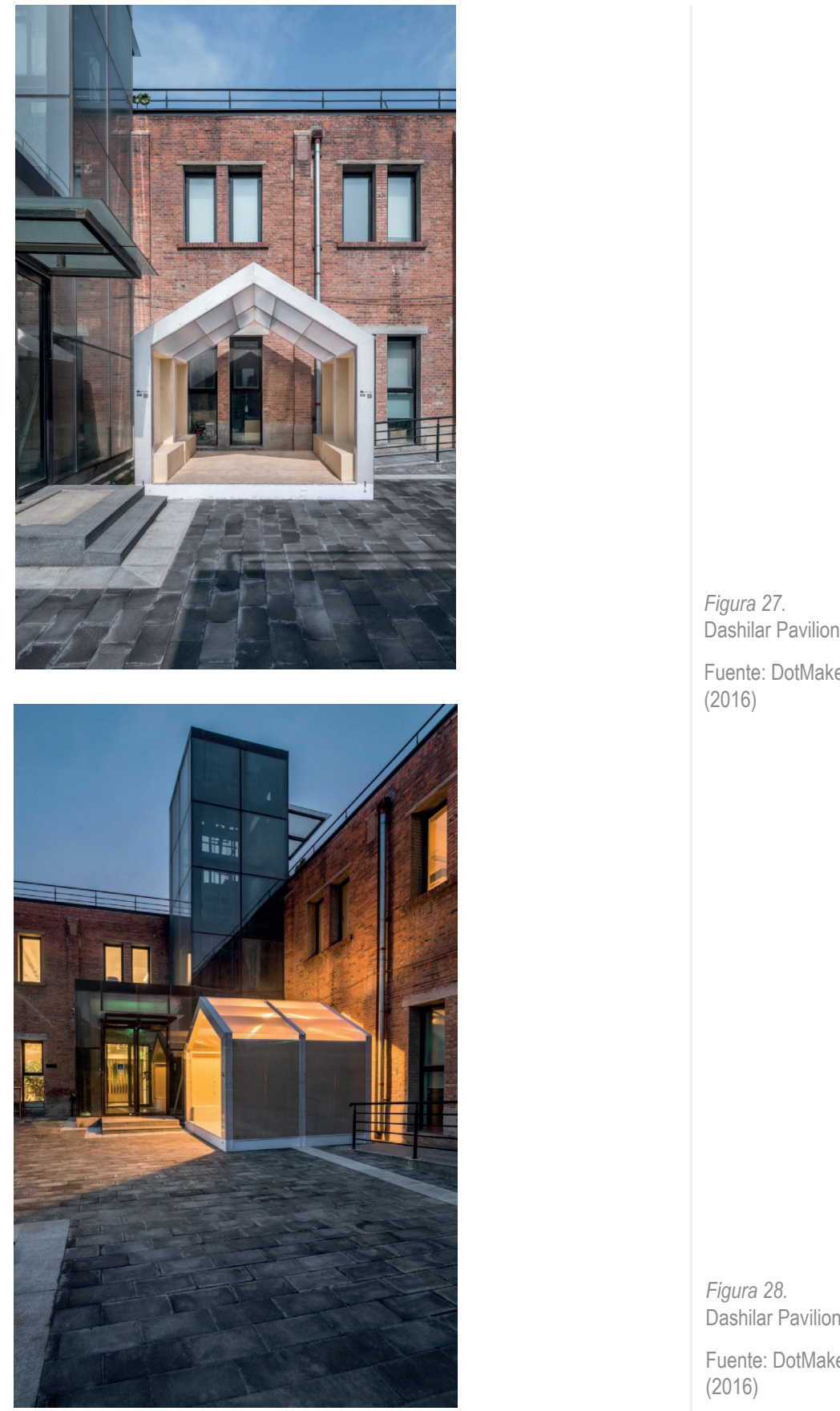

Fuente: DotMake (2016)

Figura 28.

Dashilar Pavilion

Fuente: DotMake (2016) 
Figura 29

Dashilar Pavilion

Fuente:

DotMake (2016)

Figura 30

Dashilar Pavilion

Fuente:

DotMake (2016)
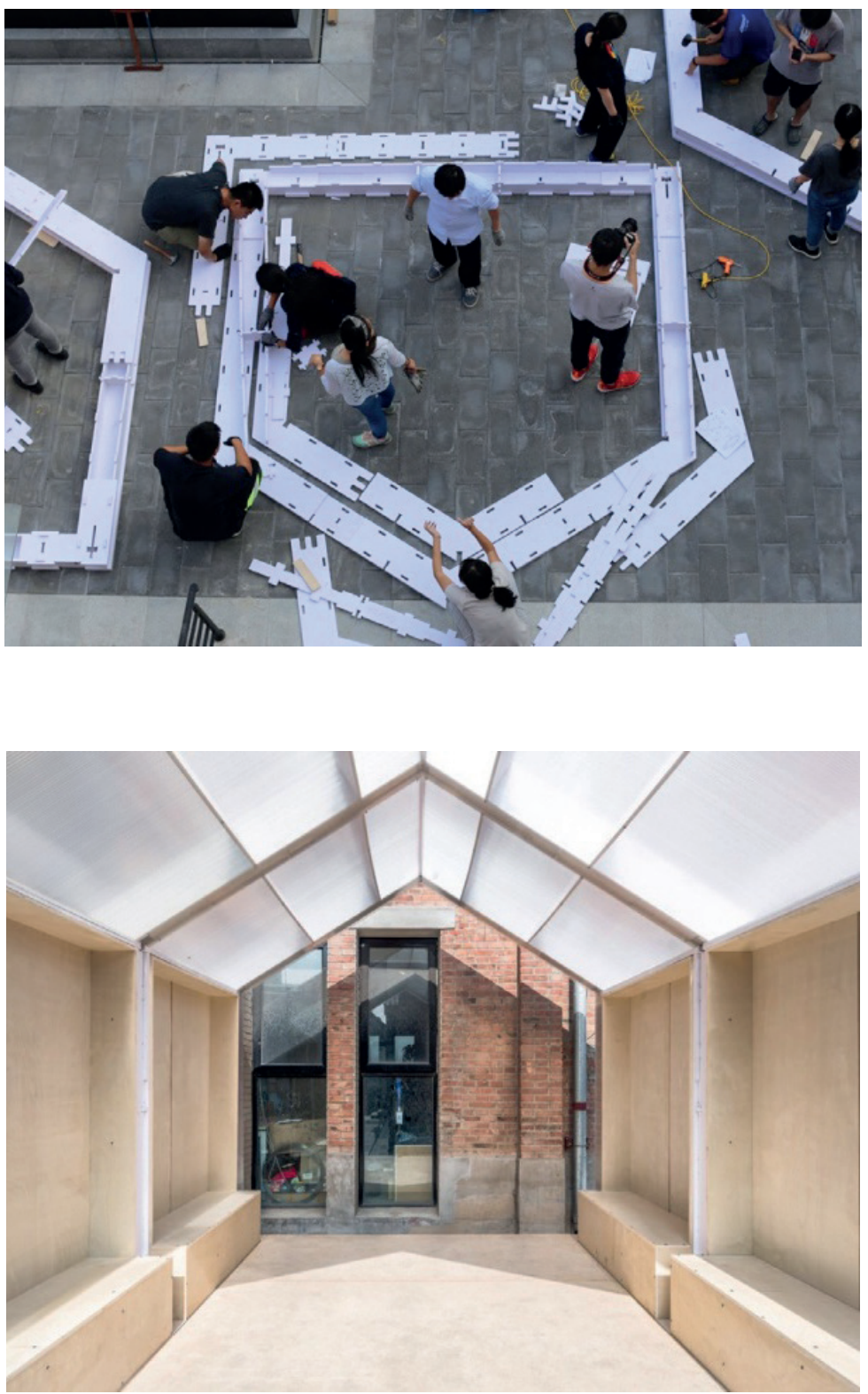


\section{Fountainbridge Community Pavilion}

Durante un fin de semana de octubre del 2015, más de cien voluntarios de entre 6 y 75 años se reunieron para montar un espacio comunitario en Fountainbridge, Edimburgo. El diseño fue realizado por la Fountainbridge Canalside Initiative adaptándose a las peculiares condiciones de uso, lugar y presupuesto. El objetivo de este proyecto era crear un lugar de uso comunitario para llevar a cabo diversas actividades como talleres de artesanía o eventos en torno a cuestiones locales relevantes como el urbanismo participativo.

\section{Análisis constructivo}

Para su construcción se usaron 70 planchas de contrachapado de madera de abeto de 18 milímetros de espesor para imprimir las piezas de la estructura de cinco pórticos a dos aguas y 1976 kilos de hormigón reciclado en la base para hacer de cimentación. En cuanto al aislamiento térmico, tiene dos tipos, uno de poliestireno y otro de tela vaquera reciclada. La membrana roja del exterior es una membrana autoadhesiva superhermética, pero permeable al vapor para liberar la condensación.

Fue construido en solamente tres días, en el primero se encajaron las piezas para formar los pórticos, en el segundo se unieron entre sí y se levantó la estructura, y el último día se colocó la membrana autoadhesiva y las ventanas y puertas, que fueron donaciones.

En septiembre de 2016 fue desmontada y todas sus partes reutilizadas o recicladas. Toda la información se puede encontrar en la web gratuitamente, tanto el manual de montaje como el modelo 3D, los planos de CAD para su impresión, así como documentos con información detallada acerca del proyecto.

\section{Conclusiones}

De nuevo, toda la estructura está montada con un sistema de machihembrado, lo que facilita su desmontaje, pero en este caso hay un problema, la membrana autoadhesiva. Puede que este elemento dificulte el desmontaje del edificio, pero, aun así, todo lo demás sigue cumpliendo con los principios de la "arquitectura circular", por lo que lo podemos considerar un buen ejemplo. 
Figura 31.

Fountainbridge Community Pavilion

Fuente:

Kobatashi (2016)

Figura 32

Fountainbridge Community Pavilion

Fuente:

Kobatashi (2016)

Figura 33

Fountainbridge

Community Pavilion

Fuente:

Kobatashi (2016)
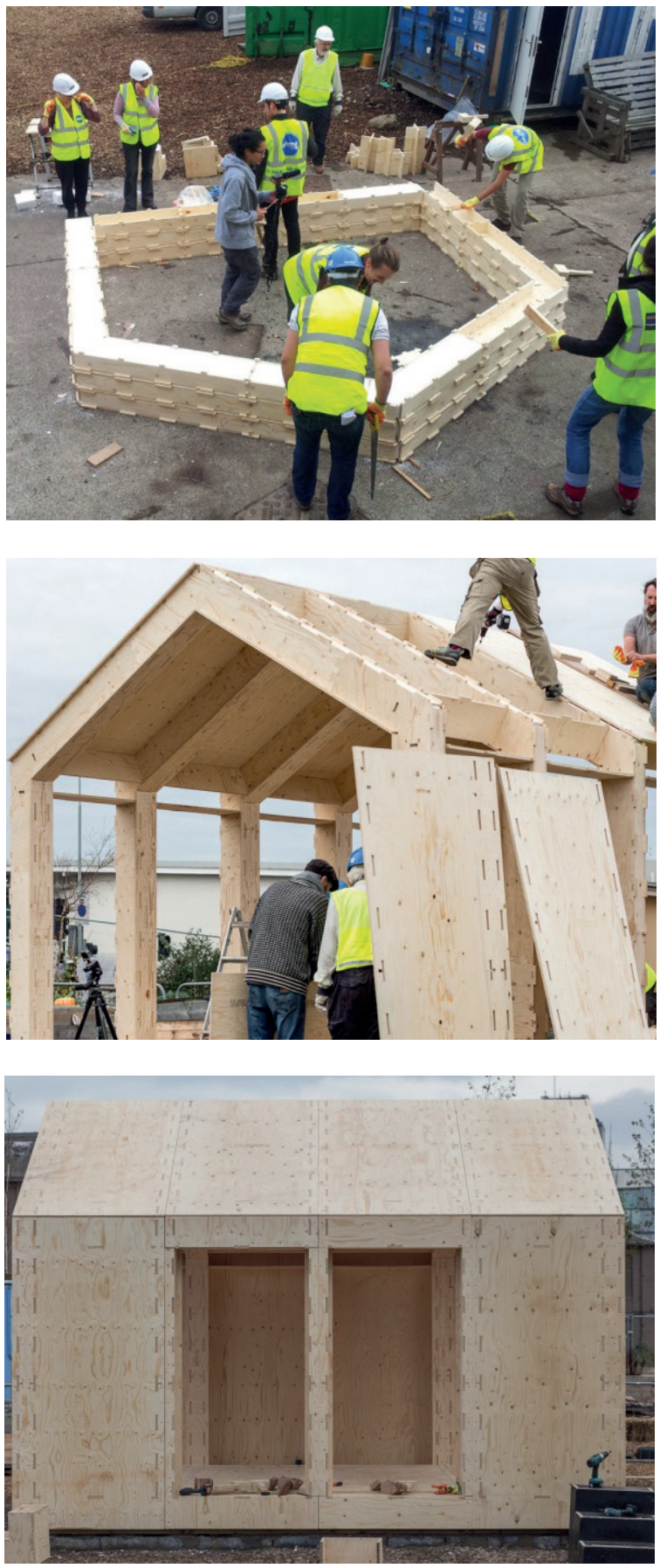


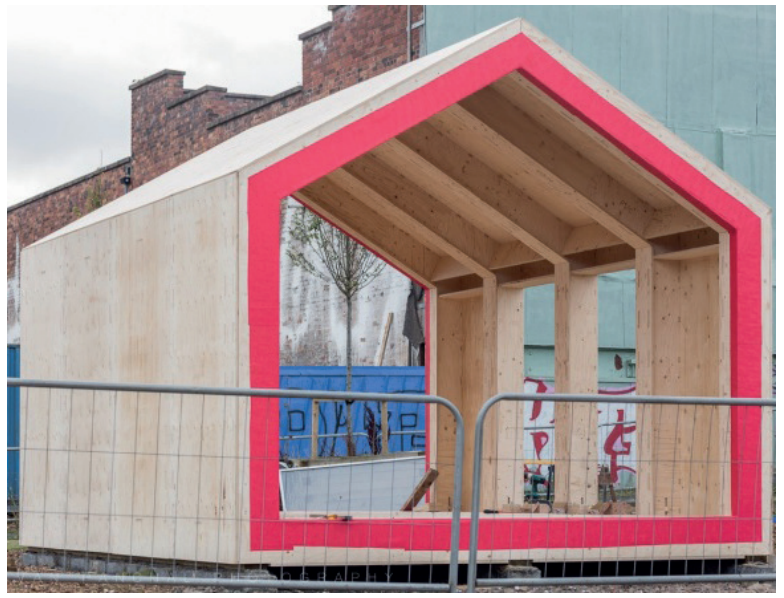

Figura 34.

Fountainbridge

Community Pavilion

Fuente:

Kobatashi (2016)

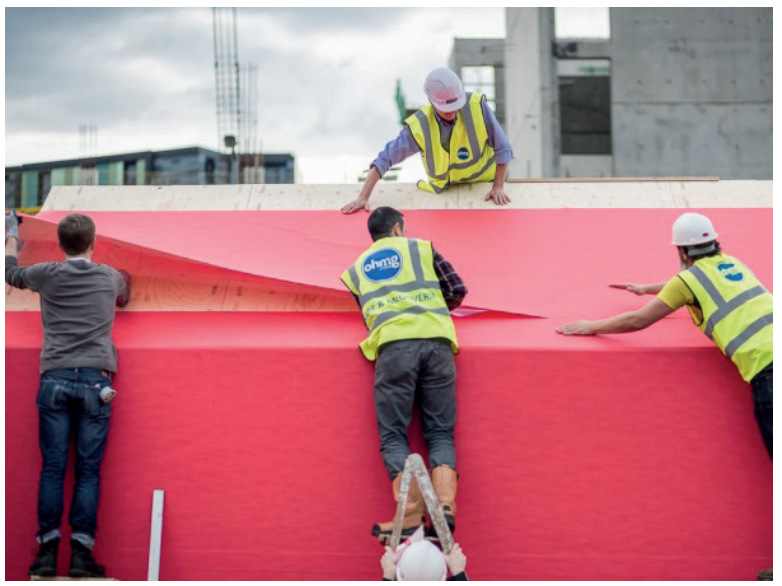

Figura 35.

Fountainbridge

Community Pavilion

Fuente:

Kobatashi (2016)

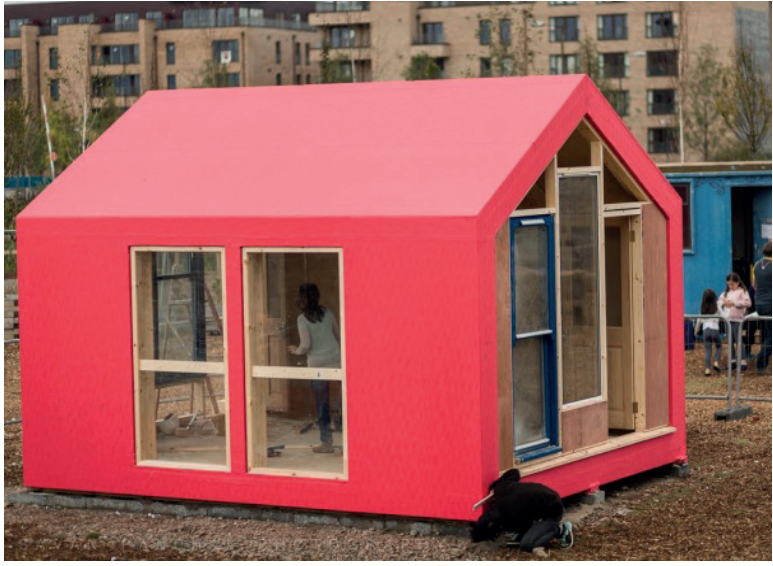

Figura 36.

Fountainbridge Community Pavilion

Fuente:

Kobatashi (2016) 


\section{RESULTADOS Y CONCLUSIONES}

Después de la realización del trabajo, se puede considerar que se ha cumplido satisfactoriamente con el objetivo propuesto y, por consiguiente, con las metas para alcanzarlo.

Tras estudiar los dos modelos, la economía circular frente a la economía lineal, se ha llegado a la conclusión de que la primera posee una serie de ventajas frente a la segunda. La economía circular propone un uso responsable de las materias primas aprovechando al máximo sus recursos y reduciendo así notablemente la generación de desperdicios y la contaminación del medioambiente, considerando los residuos como fuente principal de recursos. Asimismo, fomenta el uso de energías renovables, lo que reduce la emisión de $\mathrm{CO}_{2}$ y frena el calentamiento global, además, al minorar la producción se limita también el consumo de energía. Otra importante ventaja es el ahorro que conseguiría el sector industrial por el hecho de que el proceso más caro es el de extracción de materia prima, posibilitando la generación de más empleo y la mejoría de las condiciones laborales.

Del estudio de esta nueva corriente económica, la economía circular, se constata que debe aplicarse de arriba abajo, pero a su vez desde la base hasta la cima, es decir, para su aplicación real, debe haber una iniciativa por parte del gobierno y las grandes empresas promoviendo el modelo y siguiendo sus principios, pero al mismo tiempo cualquier persona individualmente tiene que participar desde el punto de vista del consumidor. Desde la que compra un alimento con un envase reciclable o biodegradable o un teléfono móvil de segunda mano, hasta la gran empresa que usa energías renovables para su proceso de producción. Pero al final, gran parte de la responsabilidad reside en las empresas que fabrican y desarrollan cualquiera de los productos.

En cualquier caso, del estudio realizado sobre la economía circular, se extraen los siguientes principios: uso de materiales circulares, analizar los componentes químicos de cada material y garantizar que sea admisible para ser devuelto al sistema cíclico y reemplazar o descartar para siempre aquellos que no lo sean; optimización del uso de recursos, tratar de alargar la vida de cada producto, componente o material al máximo mediante la reutilización y, en el peor de los casos, el reciclaje, ya sea en el ciclo biológico o el tecnológico; diseño sin residuos, todo tiene que estar pensado para, al final de su vida útil, poder ser reutilizado, reciclado o desmontado para que sus partes o componentes puedan serlo; planeamiento de "sistemas", entender cómo interactúan entre sí las partes de un todo para generar diseños coherentes a la hora de adquirir una categoría circular; uso de energías renovables, garantizar que los procesos de producción se alimenten de energías renovables para asegurar un impacto positivo en el medioambiente; alquiler en lugar de compra, promover el alquiler de los productos desde las empresas para hacerse cargo de la devolución al ciclo del producto y mayor satisfacción del consumidor, siempre y cuando sea posible. 
Como se ha visto a lo largo del trabajo, en la actualidad, la economía circular todavía está buscando su espacio y, aunque avanza lentamente y es un sistema que necesita mucho tiempo para ser implantado, ya hay intención de conseguir hacerlo, como así se recoge en el Informe de la Comisión Europea de 2017. Aunque en Europa algunos de los países más avanzados en este ámbito sean Reino Unido, Dinamarca u Holanda, en España también se empieza a hablar de economía circular como se puede ver en la reciente publicación del Pacto por una Economía Circular publicado en septiembre de 2017. Sin duda, es importante que las instituciones gubernamentales tomen la iniciativa de fomentar la implantación del nuevo modelo. Por otro lado, existen corporaciones como el certificado Cradle to Cradle o la Fundación Ellen MacArthur que se encargan de educar, promover y garantizar la aplicación de la economía circular en empresas, siendo unos de los grandes impulsores de esta revolución.

En cuanto a la relación entre economía circular y arquitectura, bautizado el concepto en este trabajo como "arquitectura circular", se puede ver cómo, especialmente en el norte de Europa, van un paso por delante. Es el caso de ejemplos como la empresa holandesa Desso, cuyos productos, en su mayoría moquetas, serán retornables, separables y reciclables en su totalidad, o iniciativas como la de Oostkaart, de compraventa de materiales de construcción, nacida en Holanda, pero que va propagándose ya por toda Europa. Además, como se ha visto en el análisis de casos, ya hay prototipos como el Circular Building o el ICEhouse que son claros ejemplos de "arquitectura circular", lo que supone un gran avance en el sector de cara a conocer su aplicación real. En España concretamente, al igual que en Europa, también existe una plataforma muy similar a la anteriormente nombrada Oostkaart, llamada MatMap, también dedicada a la compraventa de materiales de construcción, pero todavía no hay ningún ejemplo de "arquitectura circular" real.

En relación con el análisis de la aplicación de la economía circular en los proyectos arquitectónicos encontrados, se han sacado algunas conclusiones al respecto:

Primero: estos edificios están claramente diseñados por partes, es decir, diferenciando muy bien cuál es la función de cada material en concreto, como se puede ver en el ICEhouse que usa un material para cada parte, estructura, envolvente, acondicionamiento y revestimiento interior.

Segundo: es muy importante el diseño pensado para ser desmontado, como se puede comprobar en cualquiera de los proyectos analizados, especialmente el Circular Building y el ICEhouse. Así, se puede ver en las uniones mecánicas de las piezas estructurales, en el montaje de los paneles de los cerramientos o en la colocación de la lámina impermeabilizante en el primer caso, o en las uniones atornilladas de la estructura metálica del segundo caso.

Tercero: se ha comprobado que prima un diseño modular, lo que facilita mucho el proceso de montaje y además permite la posibilidad de realizar cambios o reparaciones en cualquiera de las partes o componentes, ya sea por causas de durabilidad u otros motivos. 
Cuarto: también es muy importante la creación de un catálogo de todos los materiales utilizados para cada proyecto y sus especificaciones como durabilidad, reciclabilidad, composición, etcétera, además de incluir una explicación de su tratamiento, cómo se debe reparar o su desmontaje. Un buen ejemplo de esto son Dashilar Pavilion o Fountainbridge Community Pavilion, en los que existe una base de datos de cada uno con los materiales usados y todas sus características y especificaciones, así como su montaje.

Quinto: como pasa en el Circular Building, es preferible el alquiler frente a la compra de componentes. Es decir, mediante un alquiler, la empresa se encarga, por ejemplo, de suministrar listones de madera para el revestimiento exterior y, cuando están en mal estado o ya no se necesitan, recogerlos para su reciclaje o reutilización, suministrando otros nuevos al cliente en caso de necesitarlos. Es un modelo que beneficiaría a la empresa, ya que recuperaría la materia prima de nuevo y al cliente, que tendría un material competente en todo momento.

Pero después de conocer los casos reales, se interpreta que todavía queda mucho camino por hacer y hoy en día tiene muchos límites. Los prototipos analizados, aparte de ser solamente experimentos, son arquitectura temporal y no están preparados para ser habitados, excepto MicroHouse que, aunque diseñado para ello, todavía está en desarrollo. Son edificios de una planta y de un tamaño pequeño, ya que si se planteara el hecho de hacer un edificio "circular" de grandes dimensiones, seguramente se complicaría mucho el diseño. Además, habría que tener en cuenta cuestiones como todas las instalaciones que contiene un edificio convencional, electricidad, fontanería, ventilación, etcétera, y habría que compatibilizar el hecho de construir con materiales "circulares" a la vez que tener en cuenta la eficiencia energética y el confort de las personas. Otra cuestión que quedaría por resolver sería la transmisión de cargas al terreno al aumentar la dimensión. De todos modos, poco a poco y mientras la sociedad avance hacia la economía circular, se irán resolviendo estas cuestiones.

Finalmente y para concluir con los resultados, se destacan una serie de principios básicos a los que debería responder una ideal "arquitectura circular":

Diseño para el desmontaje: cada componente de un edificio debe estar pensado para poder ser reparado, cambiado o desmontado sin ser dañado para su reutilización o reciclaje al final de su vida útil, teniendo en cuenta la diferencia de durabilidad de cada elemento.

Diferenciación de partes y uniones entre ellas: saber el comportamiento de cada parte del edificio, cuál es su función y cómo se relacionan las diferentes partes entre ellas. Así como las uniones, preferiblemente mecánicas, para poder ser separadas con facilidad.

Creación de un catálogo: recoger las especificaciones y características de cada material empleado en el edificio para conocer en todo momento sus 
necesidades y poder compartir las ventajas. Así como conocer la manera en que puede ser reutilizado o reciclado en un contexto circular.

Eficiencia energética: tratar de reducir al mínimo el consumo energético de los edificios.

Alquiler: conseguir materiales o productos provenientes de empresas que ofrezcan el alquiler de sus productos, para que la misma empresa se haga cargo de su reparación, reutilización o reciclaje y así evitar residuos y conseguir un mejor servicio.

En lo que concierne a la aplicabilidad de la economía circular en la arquitectura, a pesar de que es un campo muy reciente y poco desarrollado, se puede considerar que la arquitectura circular es una realidad y tiene un gran futuro por delante. Cada vez se habla más de sostenibilidad y de arquitectura sostenible. Pero, como apunta Miren León, la arquitectura circular va más allá de la arquitectura sostenible. El camino es largo, pero ya parece que se camina en esa dirección. Intenciones gubernamentales, cambios legislativos, iniciativas empresariales, diseños técnicos y demandas de consumidores pueden facilitar que se avance en este nuevo modelo más respetuoso con el medioambiente.

\section{REFERENCIAS}

Arquitectura + Acero (2016). Circular Building. Recuperado de http://www.arquitec turaenacero.org/proyectos/edificios-de-equipamiento-y-servicios-viviendaunifamiliar/circular-building

Arup. (2021). Architecture. Recuperado de https://www.arup.com/expertise/services/ buildings/architecture

Backlight [Villaggio Vivailsole]. (17 de marzo de 2013). Waste=Food [Archivo de video]. Recuperado de https://www.youtube.com/watch?v=2xhgsKenR5w [Idioma original inglés, traducido por el autor]

Bark House. (2017). Products. Recuperado de https://barkhouse.com/

Brand, S. (1994). How Buildings Learn. New York: Viking.

Braungart, M. y McDonouch, W. (2005). Cradle to Cradle (De la cuna a la cuna): rediseñando la forma en que hacemos las cosas. Madrid: McGraw-Hill Companies.

Bundles. (2017). How it works. Recuperado de https://www.bundles.nl/en/how -it-works/

Coevolving. (2006). Shearing Layers [Gráfico]. Recuperado de http://www.coevolving. com

Comienzan los trabajos de la estrategia de economía circular de la región. (20 de septiembre del 2017). La Opinión de Murcia. Recuperado de http://www.la 
opiniondemurcia.es/consejo-gobierno/2017/09/20/comienzan-trabajosestrategia-economia-circular/861258.html

Comisión Europea. (2017). Report from the Commission to the European Parliament, the Council, the European Economic and Social Committee and the Committee of the Regions on the implementation of the Circular Economy Action Plan. Recuperado de https://op.europa.eu/en/publication-detail/-I publication/391fd22b-e3ae-11e6-ad7c-01aa75ed71a1/language-en/ format-PDF

Cradle to Cradle Products Innovation Institute. (2017). Product Certification [base de datos en línea]. Recuperado de https://www.c2ccertified.org/get-certified/ product-certification-process

Cradle to Cradle. (2013). Cradle to Cradle (C2C) [llustración]. Recuperado de https:// www.c2cplatform.tw/en/c2c.php?Key=1

COTEC. (8 de marzo de 2017). Economía Circular: descubre lo que es antes de que reviente el Planeta. \#EconomíaCircular [Archivo de video]. Recuperado de https://www.youtube.com/watch?v=Lc4-2cVKxp0

Desso. (2017). Products. Recuperado de http://www.desso.in/products/

DotMake. (2016). WikiHouse Dashilar Pavilion. Recuperado de https://medium.com/ wikihouse-stories/wikihouse-dashilar-pavilion-bd470f8ad5b8

Ellen MacArthur Foundation. (2017). Building Blocks of a Circular Economy. Recuperado de https://www.ellenmacarthurfoundation.org/circular-economy/building-blocks

Fatra. (2017). Product Use: Building and Construction. Recuperado de http://www. fatra.cz/usage/stavebnictvi/

Fundación Arquia. (2 de septiembre de 2016). La nueva arquitectura sostenible: la economía circular. Recuperado de http://blogfundacion.arquia.es/2016/09/ la-nueva-arquitectura-sostenible-la-economia-circular/

Fundación Arquia. (17 de noviembre de 2016). La arquitectura en la economía circular. Cómo diseñar de manera circular. Recuperado de http://blogfundacion .arquia.es/2016/11/la-arquitectura-en-la-economia-circular-como-disenar-demanera-circular/

Fundación Economía Circular. (2015). La fundación. Recuperado de http://economia circular.org

Kobatashi, A. (2016). Fountainbridge Communty Pavilion [base de datos en línea]. Recuperado de https://www.akikokobayashi.co.uk/fountainbridge-wikihouse

Larousse. (2016). Gran Diccionario de la Lengua Española. Recuperado de https:/l www.larousse.es/

León, M. (2017). La nueva arquitectura sostenible: La economía circular. Recuperado de https://blogfundacion.arquia.es/2016/09/la-nueva-arquitectura-sostenible -la-economia-circularl 
MAPAMA. (2017). Pacto por una economía circular: el compromiso de los agentes económicos y sociales 2018-2020. Recuperado de https://www.miteco.gob. es/es/calidad-y-evaluacion-ambiental/temas/economia-circular/pacto/

MatMap. (2017). Nuestro concepto. Recuperado de https://www.matmap.com/sobrenosotros

McDonough, W. (2016). William McDonough's ICEhouse ${ }^{\mathrm{TM}}$ Debuts in Davos. Recuperado de http://www.mcdonough.com/william-mcdonoughs-icehouse-de buts-in-davos/

Oficina Europea de Estadística (EUROSTAT). (2016). Municipal Waste Generation and Treatment, by Type of Treatment Method [base de datos en línea]. Recuperado de https://ec.europa.eu/eurostat/databrowser/view/cei_wm011/ default/table?lang=en

Oostkaart. (2017). Harvest Map. Recuperado de https://www.oogstkaart.nl/

Passive Haus Institute. (2017). About Passive House-What is a Passive House? Recuperado de http://www.passivehouse.com/02_informations/01_whatisapassive house/01_whatisapassivehouse.htm

PSD Graphics. (2011). Green Recycling Symbol [Gráfico]. Recuperado de https:// www.psdgraphics.com/file/green-recycling-symbol.jpg

Real Academia Española de la Lengua (RAE). (2014). Reutilizar. En Diccionario de la lengua española. Recuperado de http://dle.rae.es/?id=WMGvvdn

Roberts, S. (2016). ICEhouse Designed for Continuous Reuse and Quick Construction. Recuperado de https://newatlas.com/william-mcdonoughpartners-icehouse/41470/

Significados. (2013-2017). Reciclar. En Significados.com. Recuperado de https://www. significados.com/reciclar/

Smith, S. (2016). Circular Building 2016 [Archivo de video]. ARUP. Recuperado de https://www.arup.com/perspectives/the-circular-building

TEDx Talks (Webster, K.). (30 de enero de 2012). TEDxLoodusele- Ken WebsterCircular Economy [Archivo de video]. Recuperado de https://www.youtube. com/watch?v=mvQEBB3ldZM\&t=508s

The Circular Economy: Interview with Walter Stahel. (5 de julio del 2013). Making It Magazine. Recuperado de http://www.makingitmagazine.net/?p=6793

Vivailsole V. (17 de marzo del 2017). Waste=Food [Archivo de video]. Recuperado de https://www.youtube.com/watch?v=2xhgsKenR5w

William McDonough [Hub Culture]. (21 de enero de 2016). Davos 2016 Hub Culture Interview w William McDonough, Architect of the ICEhouse [Archivo de video]. Recuperado de https://www.youtube.com/watch?time_continue $=11 \& \mathrm{v}$ $=0$ KHhyUJNQOE

WikiHouse. (2017). MicroHouse. Recuperado de https://wikifab.org/wiki/MicroHouse

William McDonough + Partners. (2016). ICEhouse. Recuperado de http://mcdonough partners.com/projects/icehouse/ 
ANEXO

\section{ENTREVISTA A MIREN LEÓN}

¿Cree que la sociedad actual está preparada para aplicar correctamente la economía circular? Si no, ¿cuánto tiempo crees que necesitará y de qué depende?

Creo que como sociedad estamos perfectamente preparados para aplicar la economía circular, pero aún nos queda mucho camino por recorrer. Somos gente de costumbres y de resultados a corto plazo, y culturalmente nos cuesta mucho realizar este tipo de cambios tan grandes si no vemos resultados inmediatos. Son solo unas pocas empresas, organizaciones y universidades quienes están dando pequeños pasos hacia la aplicación de los principios de esta economía.

Pero este proceso de cambio va a llevar tiempo...Y dependerá mucho de la legislación, que es la otra razón por la que nos inclinamos al cambio: cuando nos obligan o nos penalizan por hacer o no hacer algo. Actualmente, los cambios legislativos que vienen desde Europa y los instrumentos de financiación son los que están empujando el desarrollo de iniciativas hacia la economía circular, pero todavía de manera muy puntual.

En los próximos años van a ir apareciendo cada vez más iniciativas basadas en la re-utilización de materiales para el diseño de productos, productos cada vez más sostenibles y envases biodegradables, pero hace falta un cambio global de modelos de negocio que se basen en la recirculación de componentes y productos y este es un cambio muy grande, que supone cambios en procesos de diseño y producción. Y tanto empresas como consumidores tenemos que cambiar culturalmente para poder llevarlo a cabo, y eso no se produce de la noche a la mañana, lleva años.

¿Para usted, qué diferencia la arquitectura sostenible de la arquitectura circular? ¿Hay diferencias o una contiene a la otra?

Para mí el concepto de arquitectura circular va más allá del de arquitectura sostenible. Creo que la arquitectura circular es sostenible, pero eso no quiere decir que la arquitectura sostenible sea siempre circular. Ahora mismo la arquitectura sostenible habla mucho de eficiencia energética y de materiales de construcción, de Passivehaus y de edificios de consumo casi nulo. Eso está muy bien, es necesario que diseñemos edificios que consuman menos energía y a poder ser que la necesiten menos. Pero ahora no se está teniendo en cuenta qué pasará con estos edificios cuando termine su vida útil, que es lo que pretende la arquitectura circular.

En realidad, con la rapidez con la que evoluciona la sociedad es difícil pensar qué pasará con un edificio dentro de cincuenta o cien años, y qué necesidades tendremos nosotros como usuarios. Pero ese es el reto para 
la arquitectura circular, llegar a una concepción global de la arquitectura que nos lleve a diseñar desde el principio pensando en todo el ciclo de vida de la edificación, incluyendo su futura reutilización o la demolición de la misma. Y de este modo crear soluciones arquitectónicas que se adapten de la mejor manera posible a los cambios que se puedan producir, y cuyos componentes puedan reutilizarse una vez llegado el fin de su vida útil.

\section{¿Dónde diría que se ha avanzado más en este ámbito?}

En Holanda sin duda. Son un poco los precursores de la economía circular, y tienen un plan para convertirse en un país circular. También en Reino Unido y Dinamarca, existen programas para convertir Londres y Copenhague en ciudades circulares, algo que Ámsterdam también busca. A escala más pequeña, los primeros intentos de edificación circular se encuentran en estos países.

¿Piensa que sería posible construir una vivienda que aplique el sistema circular en España hoy en día? ¿Espejismo o realidad?

Pues hoy en día creo vamos en camino, pero aún no es del todo posible. Ya no por la dedicación e investigación necesaria; cada vez existen más ejemplos de viviendas prefabricadas que ya inciden un poco en el tema del desmantelamiento, pudiendo desmontarlas y cambiarlas de sitio.

Pero ahora mismo estamos centrados en otra cosa. La arquitectura sostenible está derivando hacia el Passivehaus, que es un buen camino hacia la eficiencia energética y el consumo casi nulo de energía, pero creo que además de aplicar estos conceptos deberíamos darle una vuelta de tuerca más al concepto, al diseño. No solo por utilizar materiales sostenibles o reutilizados vamos a ser circulares. Hay que ser circular desde el diseño, y eso es algo que cuesta un poco más llevar a cabo. Sobre todo por la falta de costumbre de pensar en el futuro, y por falta de formación y conocimiento sobre la economía circular. 